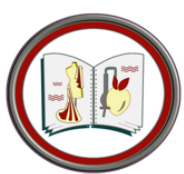

$$
\begin{gathered}
\text { جامعة المنوفية، شبين الكوم، مصر المنزلي } \\
\text { https://mkas.journals.ekb.eg }
\end{gathered}
$$

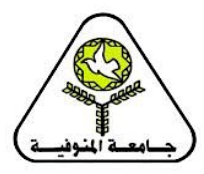

كلية الاقتصاد المنزلي

$$
\text { الملابس والنسيج }
$$

\title{
توظيف مختارات من زخارف الفن الإسلامي لإثراء القيمة الجمالية لملابس الفتيات في مرحلة الطفولة المتأخرة
}

نشأت نصر الرفاعي، مني حمدي الفرماوي، ماجدة إبراهيم الأسود، شيماء شديد عبد الجواد زهره قسم الملابس والنسيج، كلية الاقتصاد المنزلي، جامعة المنوفية، شبين الكوم، مصر

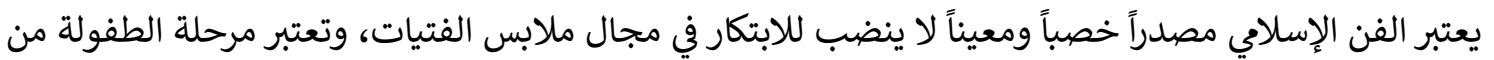

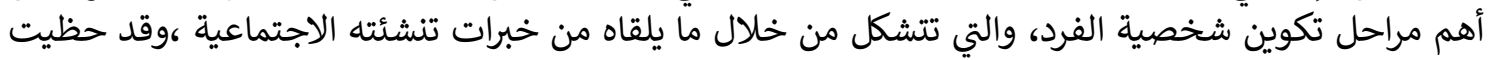

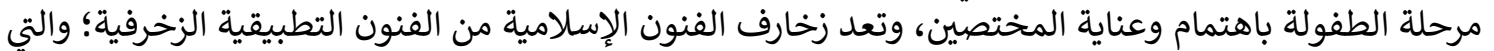

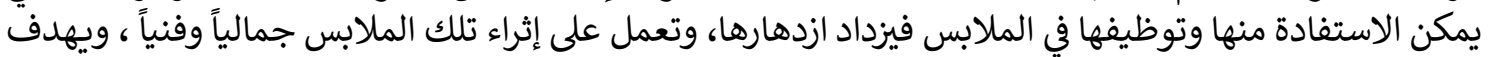

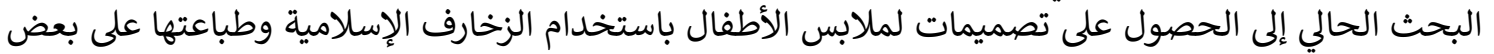

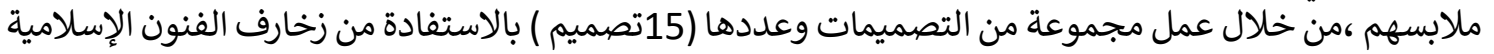

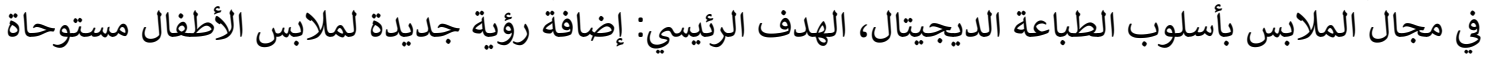

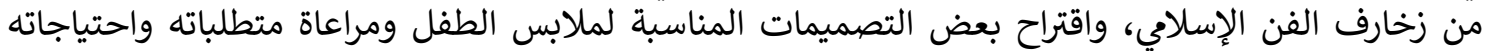

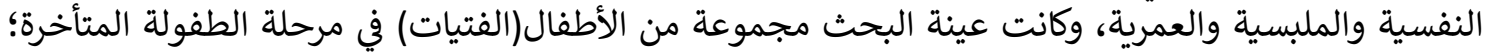

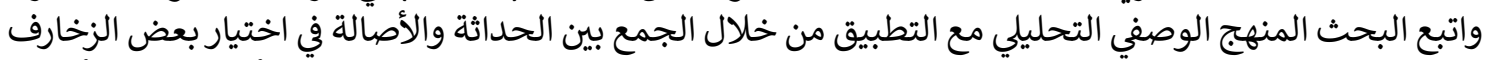

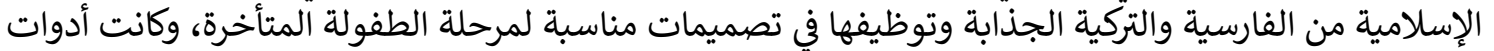

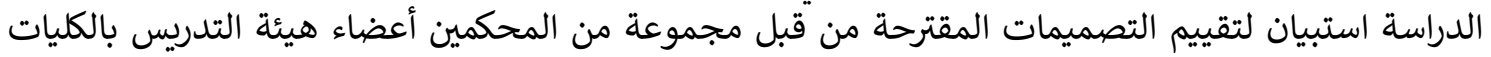

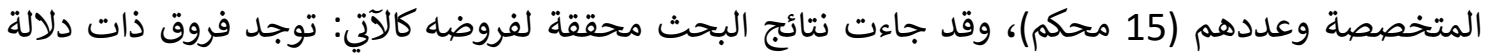

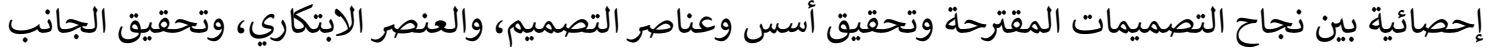

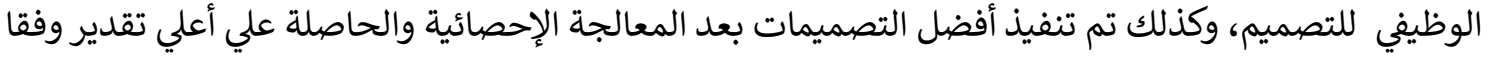

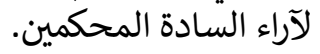

الكلمات المفتاحية: الفن الإسلامي، التصميم الزخرفي، الطفولة المتأخرة، الزخرفة الإسلامية.

مقدمة:

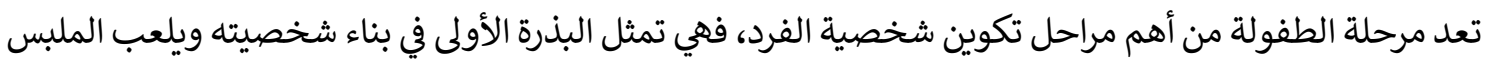

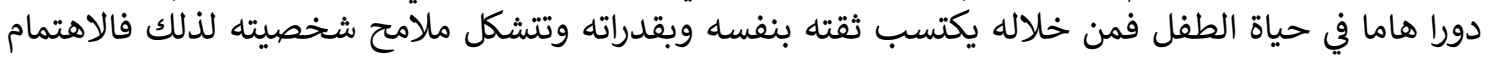


بخطوط ملابس الأطفال وتصميماتها والخامات التي تصنع منها مطلبا مهما يتم من خلاله إشباع احتياجات الطفل وفقا لمراحل نموه (نها فتحي: 2012 الإطفا وتهم).

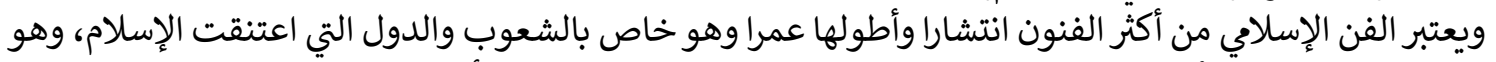

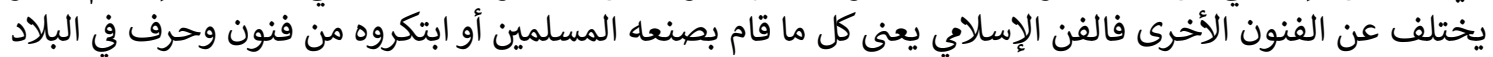

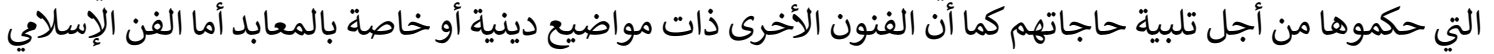

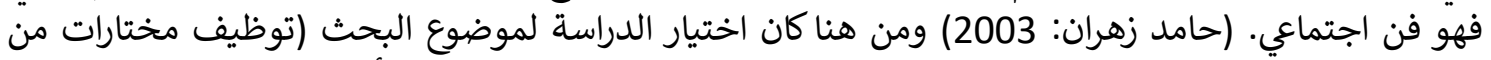

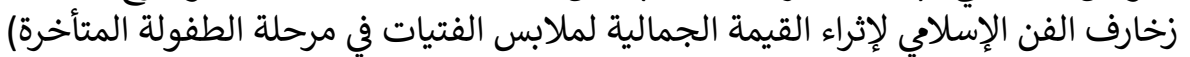
مشكلة البحث:

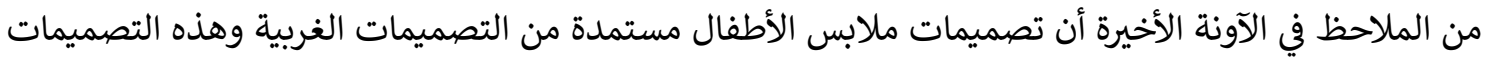

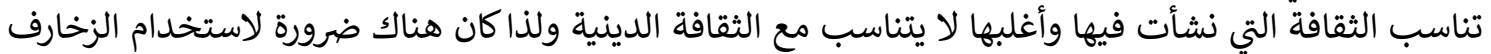

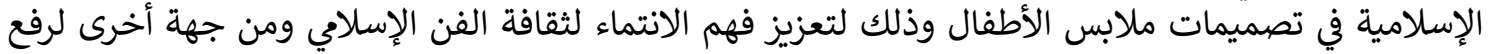
القيمة الجمالية لملابس الأطفال. ومما سبق يمكن صياغة المشكلة في التساؤلات الآتية:

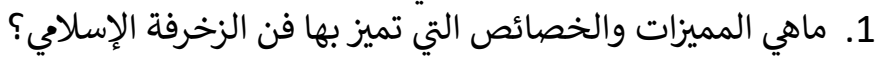

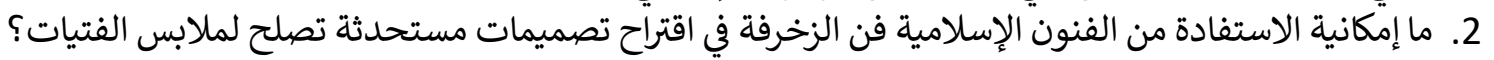

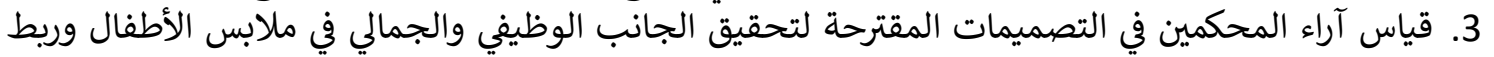
مجال الملابس بالفنون.

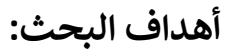

1. إضافة رؤية جديدة لملابس الأطفال مستوحاة من زخارف الفن الإسلامي.

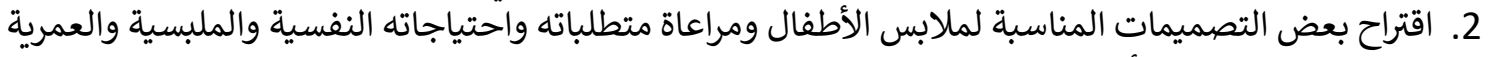
في مرحلة الطفولة المتأخرة. 3. استحداث مجموعة من التصميمات تناسب الفتيات في مرحلة الطفولة المتأخرة من خلال طباعة الزخارف

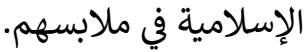

4. قياس آراء ألمحكمين في التصميمات المات المقات المترحة لتحقيق الجانب الوظيفي والجمالي في ملابس الأطفال وربط

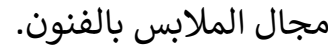
أهمية البحث: • التأكيد على أصالة زخارف الفن الإسلامي في جميع المجالات بصفة عامة، ومجال تصميم الأزياء بصفة خاصة.

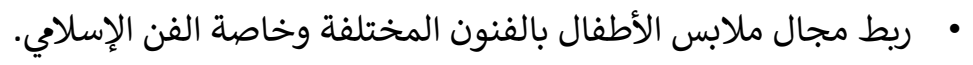

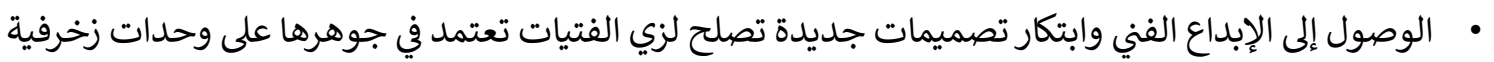
مقتبسة من الفن الإسلامي. فروض البحث: • توجد علاقة ذات دلالة إحصائية بين درجة قبول ونجاح التصميمات المقترحة لتحقيق أسس وعناصر التصميم. توجد عافي • توجد فروق فردية بين درجة قبول ونجاح التصميمات المقترحة لتحقيق العنصر الابتكاري. 
• توجد علاقة ذات دلالة إحصائية بين درجة قبول ونجاح التصميمات المقترحة لتحقيق الجانب الوظيفي

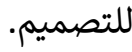

إجراءات الدراسة:

أدوات الدراسة:

• استخدام الحاسب الآلي في إعداد التصميمات المقترحة من خلال برنامج (برنامج فوتوشوب - برنامج

مارفيلوس (اصدار 2019)

• إعداد استبيان لتقييم التصميمات المقترحة من قبل السادة المحكمين.

عينة الدراسة:

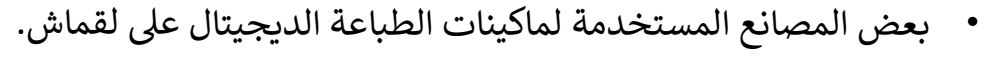

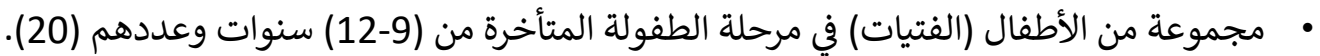

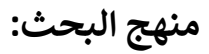
يتبع البحث الحالي المنهج الوصفي مع التحليل والتطبيق. حلدود البحث: - الحدود البشرية: مجموعة من الأطفال (الفتيات) من سن (9-12) سنوات.

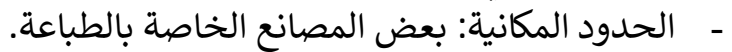

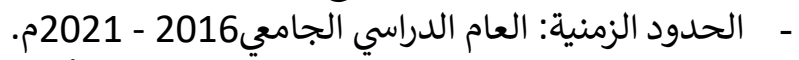

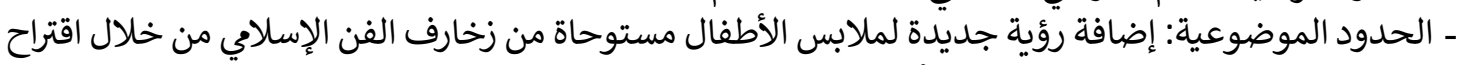

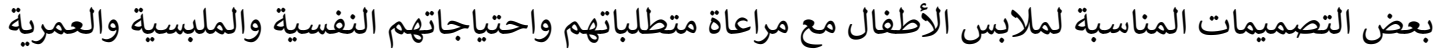

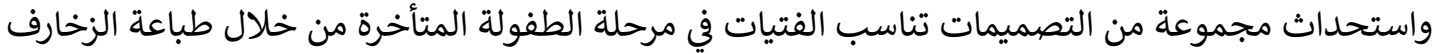

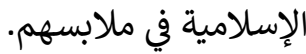
مصطلحات البحث:

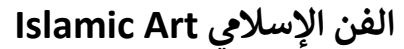

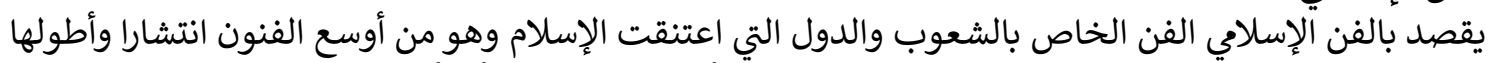

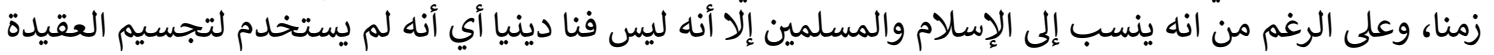

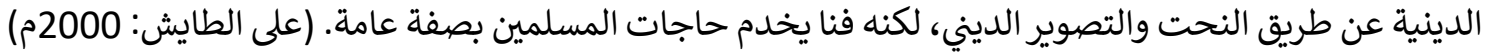

الزخارف:Ornaments الزخرفة: من اهم الفنون التشكيلية وأعظمها أثرا في إكساب معظم المنتجات الحرفية ومختلف الصناعات قيما

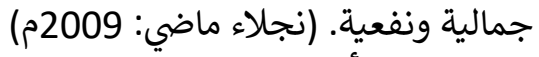
الطفولة المتأخرة:Late Childhood

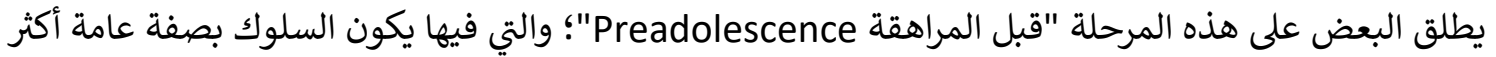

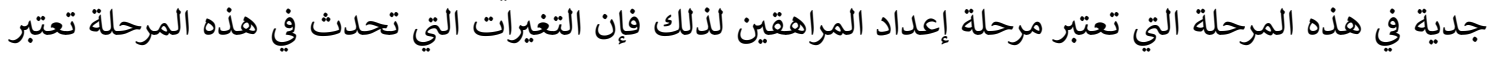

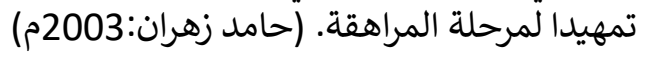
الدراسات السابقة:

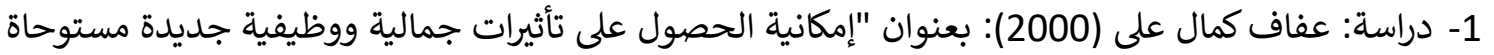

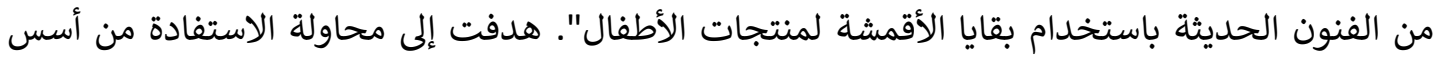




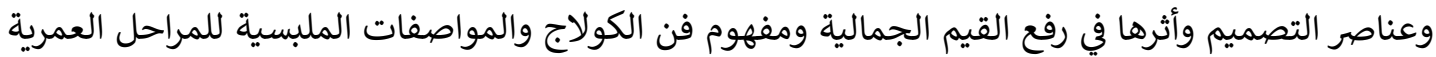

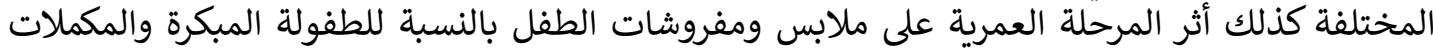

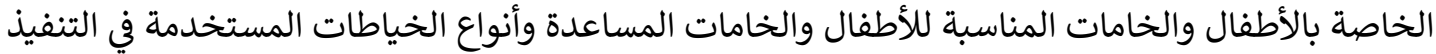

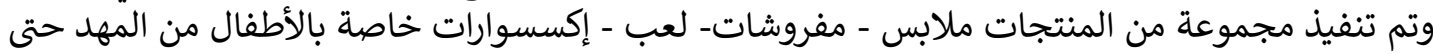

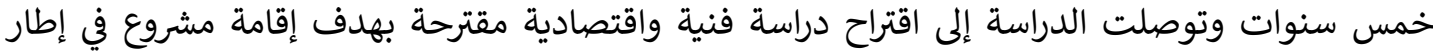
الصناعات الصغيرة للشباب الخريجين.

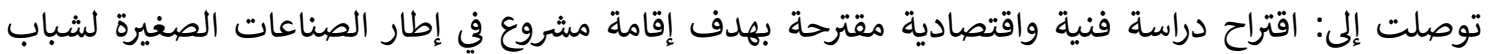

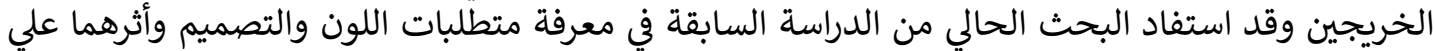
الطفل.

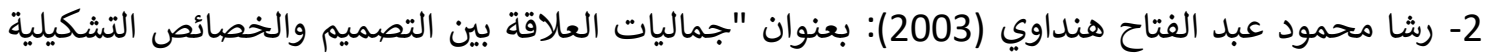

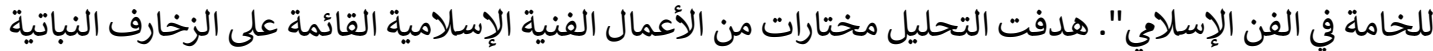

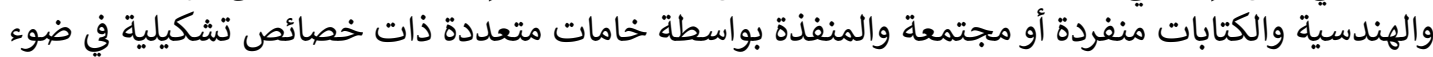
تعدد مداخل التوظيف الجمالي. توصلت إلى: توظيف الإمكانات الجرافيكية للحاسب الآلي - الكمبيوتر - كبديل غير تقليدي للتقنيفيات التنفيذية،

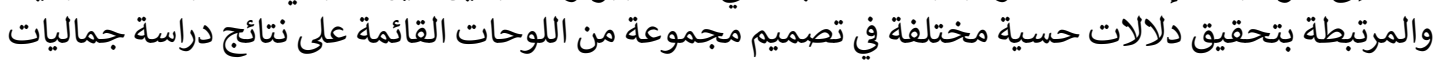

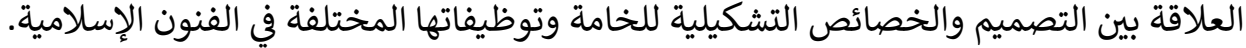

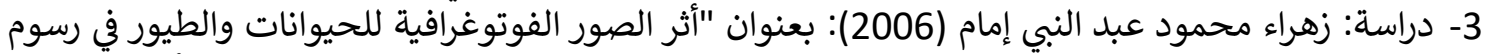

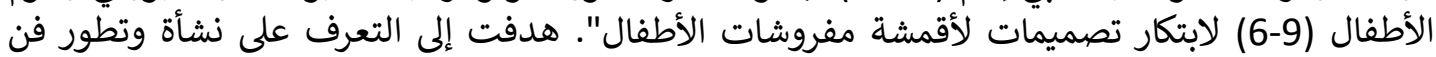

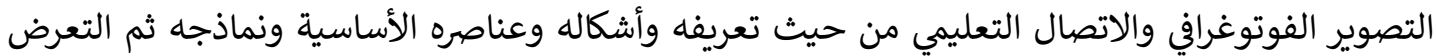

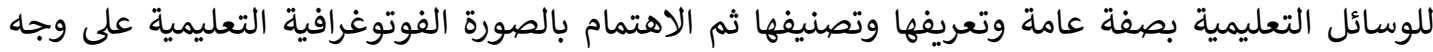

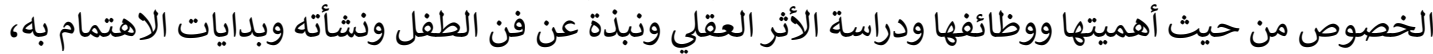

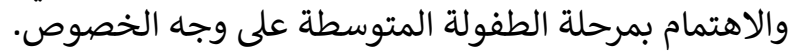

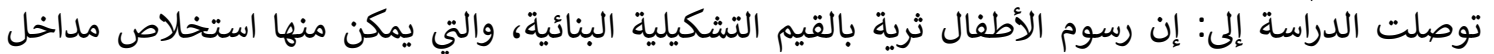

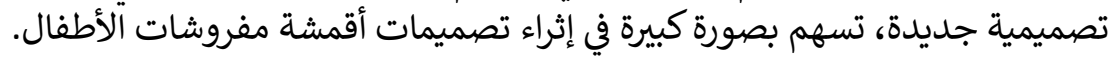

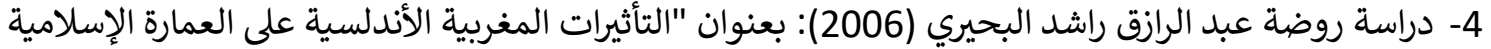

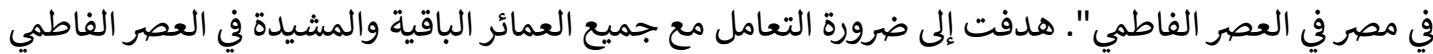

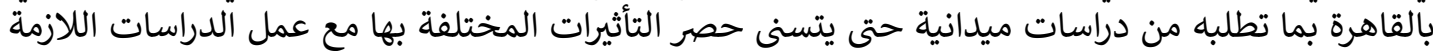
للتعرف على أصولها وسماتها الخاصة. توصلت إلى :أن التأثيرات المغربية والأندلسية في العمارة تؤثر بشكل واضح من المغرب إلى المشرق أثناء العصر الفاطمي على العمارة المصرية. مفهوم تصميم الأزياء: الإطار النظري:

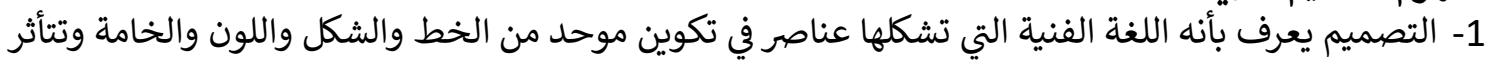

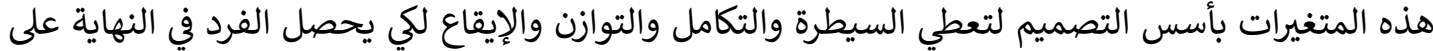
زي يشعره بالتناسق ويريطه بالمجتمع الذي لتعي النيطيط فيه. 
1- القدرة على الملاحظة باستخدام كل الحواس المتاحة. 2- القدرة على التخيل والتنظيم وريط المعلى بالستخام الموات والأشكال في البيئة المحيطة واكتشاف العلاقات والقوانين في

3- القدرة على ممارسة التجارب في حل المشكلات الفنية البسيطة.

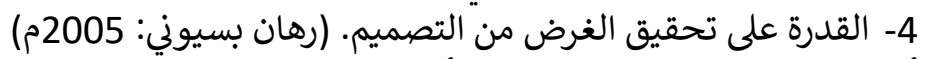

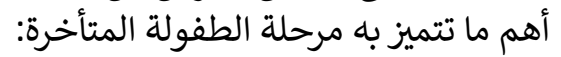
1- بطء معدل النمو بالنسبة لسرعته في المرحلة السابقة والمرحلة اللاحقة.

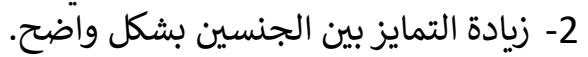

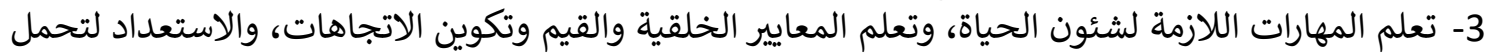

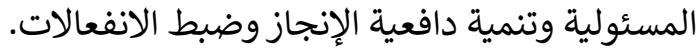

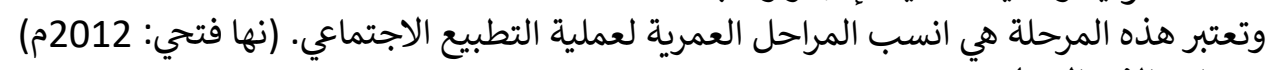

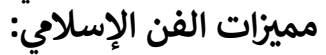
1- التنوع: يتميز الفن الإسلامي بتنوع كبئ الفير في الأشكال والتكوينات الزخرفية إلى الدرجة التي يتعذر معها أن نجد فيه تحفتين متماثلتين.

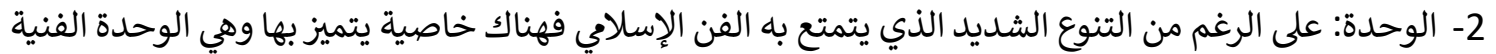

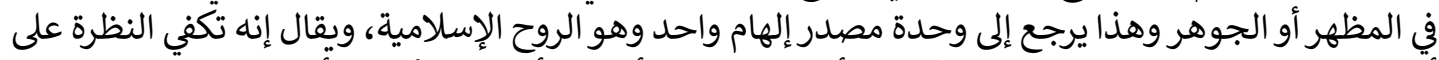

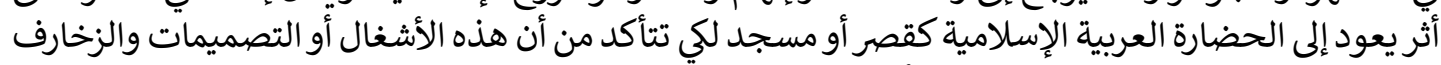

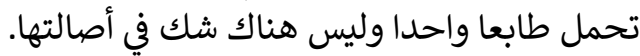

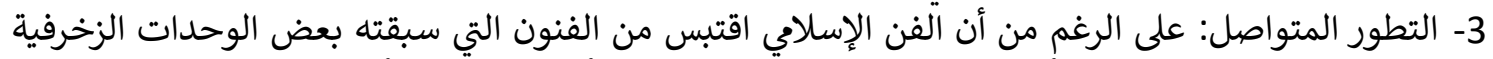

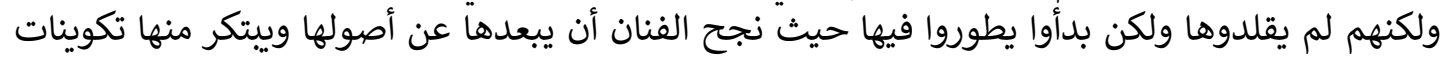
زخرفية.

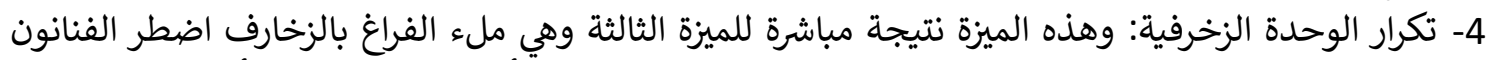

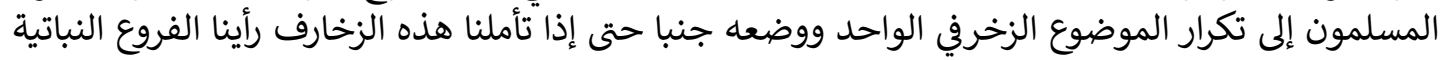

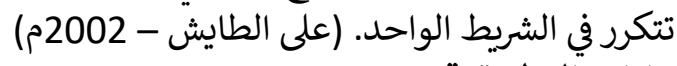
الإجراءات التطبيقية

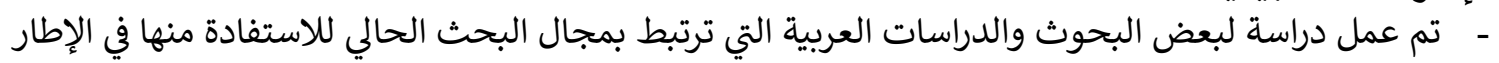

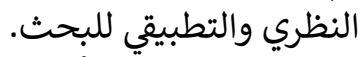
- اختيار مجموعة من أبرز اللوحات والأعمال الفنية والصور للزخارف الإسلامية الفارسية والعثمانية للاقتباس منها في التصميمات المقترحة.

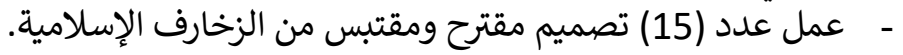

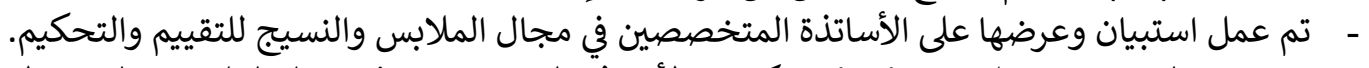

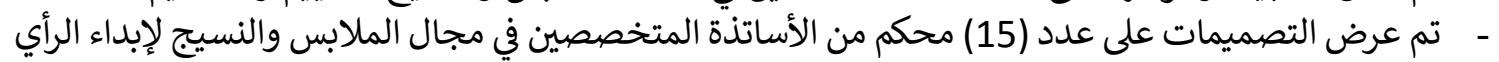

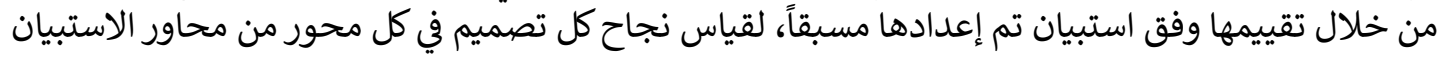

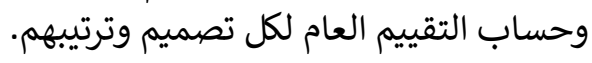
- ـ تم إدخال البيانات إلى برنامج التحليل الإحصائي "SPSS" استعدادا لعملية المعالجة واستخلاص النتائج. 
- تم إجراء المعالجات الإحصائية لنتائج الاختبارات ثم تفسيرها للإجابة عن تساؤلات البحث والتأكد من صحة

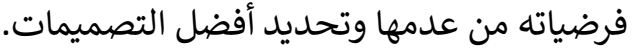

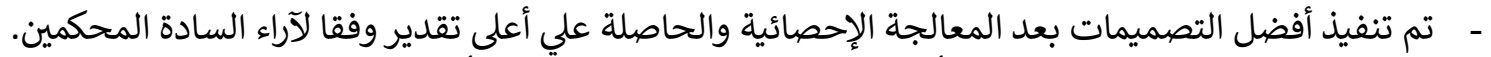

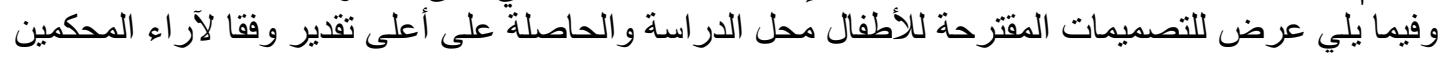
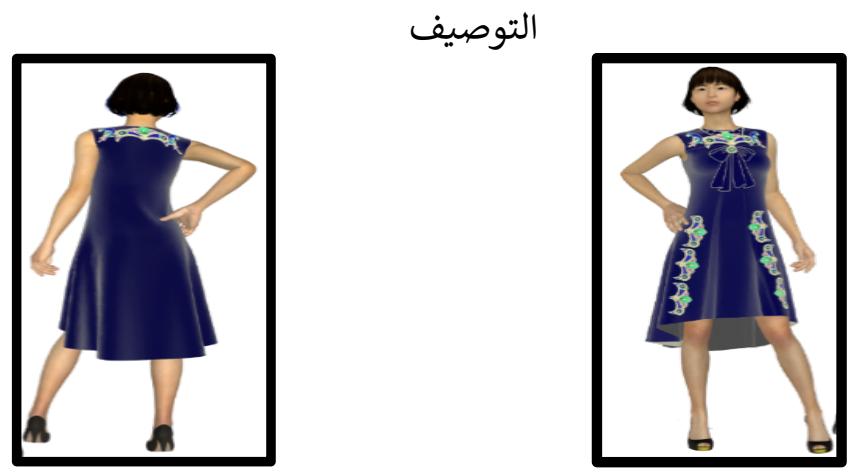

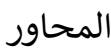

توصيف الخلف: قصة خلفية أسفل

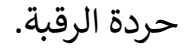

توصيف الأمام: فستان به قصه علي الصدر

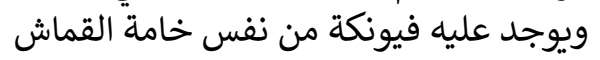
والفستان قصير من الأمام طويل فن من في الخلف.
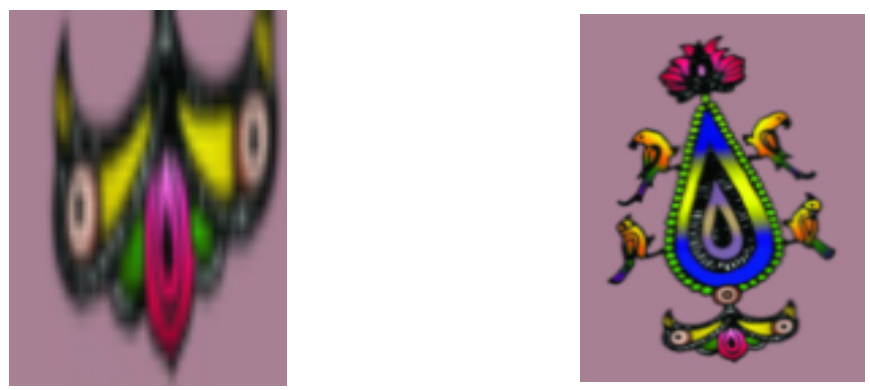

توصيف التصميم رقم

(1)

$$
\begin{aligned}
& \text { إسلامية - فارسية. } \\
& \text { موجود علي الصدر والخلف من الأعلى على جانبي الفستان. } \\
& \text { ليكرا جينز. } \\
& \text { كحلي. } \\
& \text { أخضر وبنفسبي وأصفر. }
\end{aligned}
$$

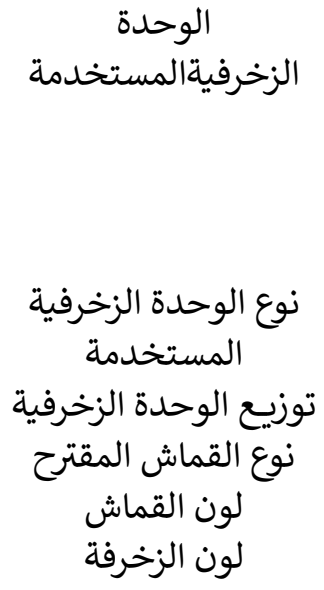

JHE, 2021, 31(3): pp 132-160- يتم طباعتها في جامعة المنوفية، جميع حقوق الطبع محفوظة للمجلة. 


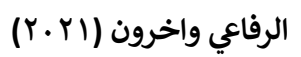
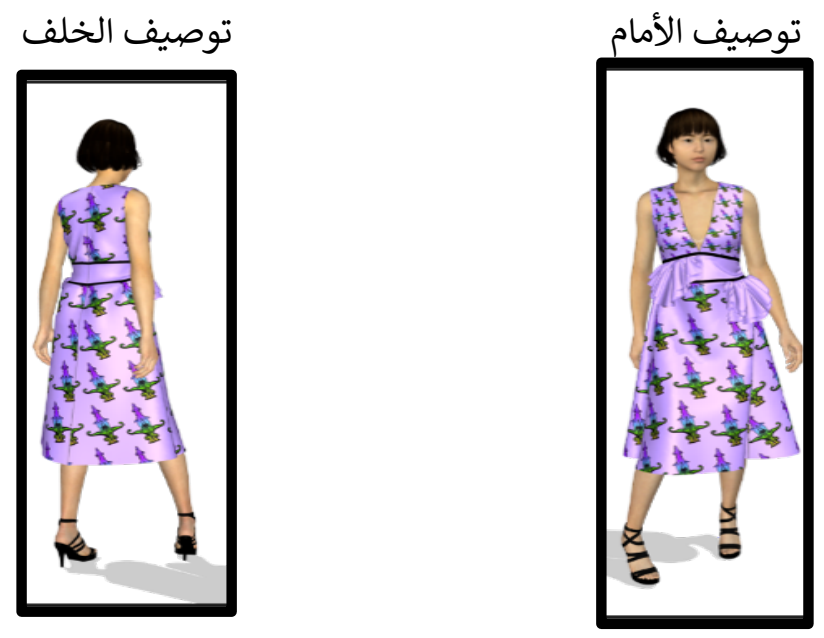

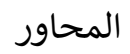

توصيف التصميم (2)

توصيف الخلف: قصة عند خط امتداد قصة

الأمام عند الوسط ويوجد سوسته خلفية.

توصيف الأمام : فستان به فتحة

ديكولتيه على شكل (V) ويوجد به الأه فيه

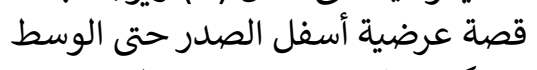

مركب عليها درابيهات من الجانبين.

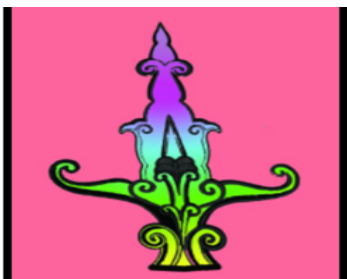

$$
\text { الوحدة الزخرفية }
$$

إسلامية - تركية.

كامل الفستان (الأمام والخلف) عدا الدرابيهات على الأجناب.

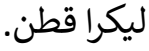
موف فاتح.

بنفسجي وأخضر وأزرق.
نوزع الوحدة الزخرفية توزيع الوحدة الزخرفية نوع القماش المقترح

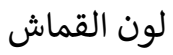
لون الزخرفة

JHE, 2021, 31(3): pp 132-160- يتم طباعتها في جامعة المنوفية، جميع حقوق الطبع محفوظة للمجلة. 


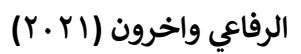
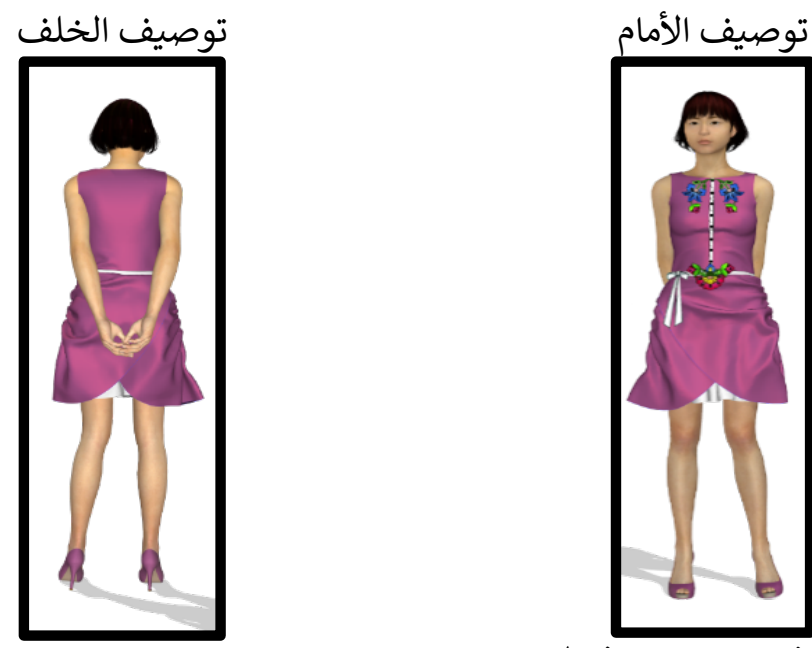

المحاور

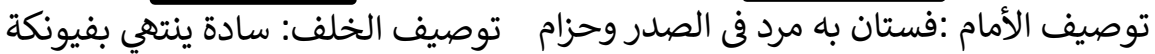

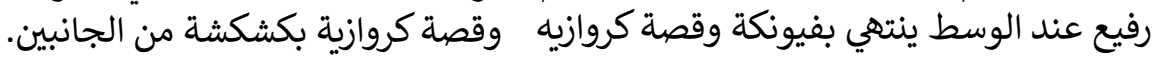
بكشكشة من الجانبين.
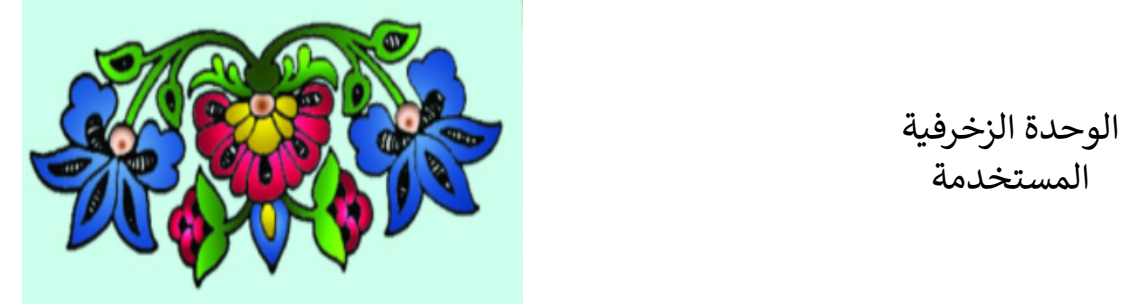

$$
\text { إسلامية - فارسية. }
$$

نوع الزخرفة

المستخدمة الزخدة

توجد على حزام المرد وعلى جانبي الوسط.

توزيع الوحدة المستخدة

الزخرفية

كشمبر غامق.

نوع القماش القخاش

لون القماش نوع القماش

أزرق وأخضر فاتح وأحمر.

لون الزخرفة 


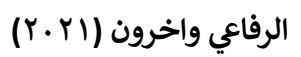
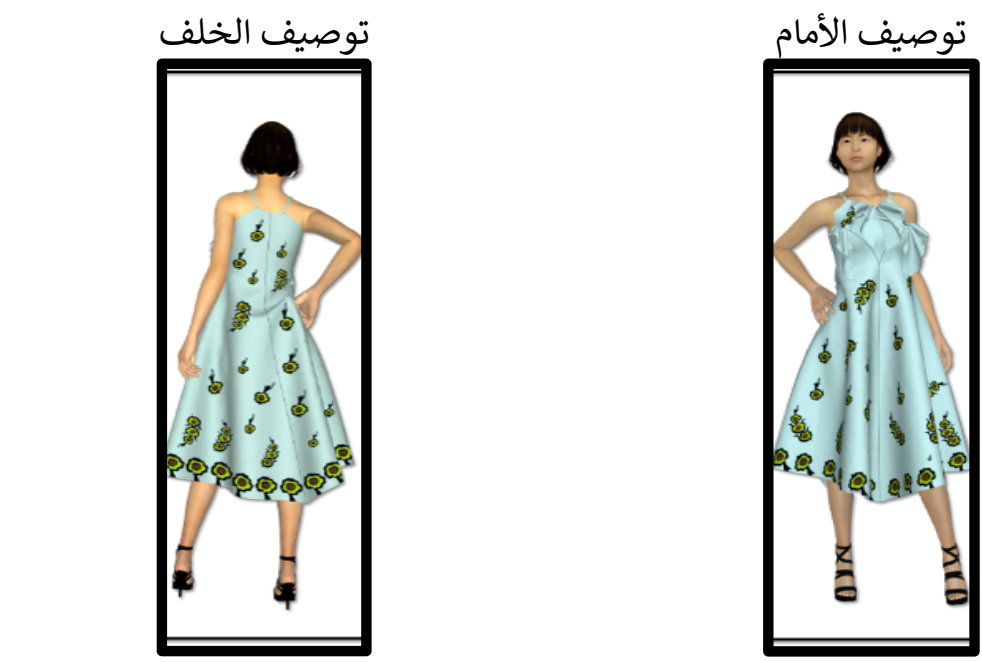

المحاور

توصيف الخلف: قصات طولية بطول

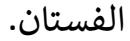

توصيف الأمام : فستان يوجد قصات

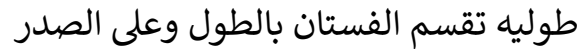
أيضا كرانيش موزعه بشكل عشوائى.

توصيف التصميم

(4)
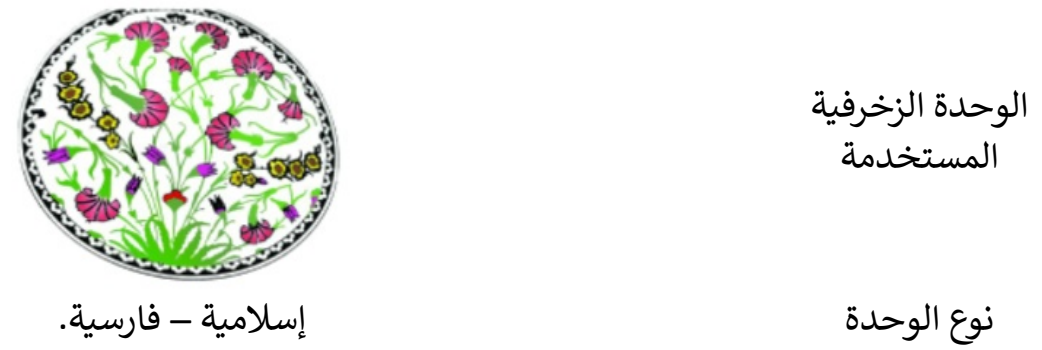

على شكل ورد مختلف الأحجام والأشكال متداخل بطريقة عشوائية.

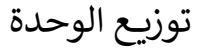
الزخرفية

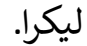

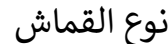
المقترح ابيض.

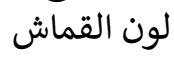




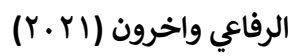

بنى غامق وأصفر.

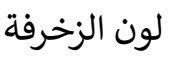

توصيف الخلف

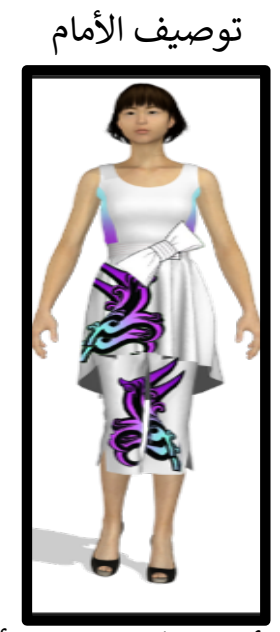

المحاور

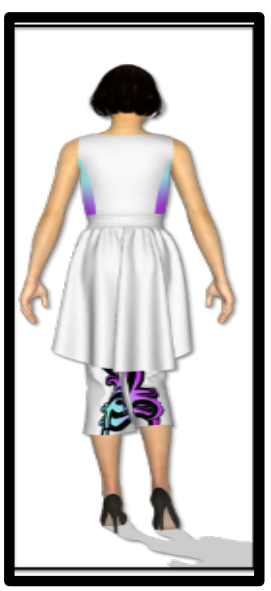

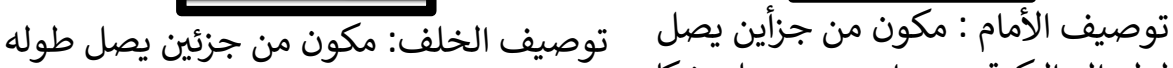

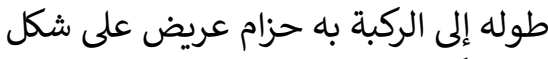

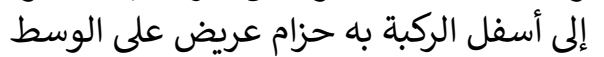

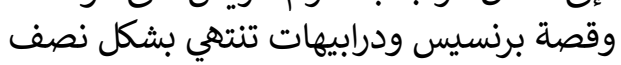
دائرى.

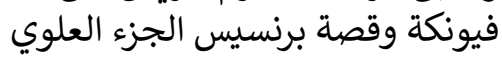
ودرابيهات تنتهي بشكل نصفئ برئن دائرة

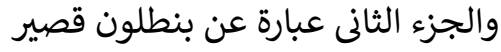
بفتحتين جانبيتين.
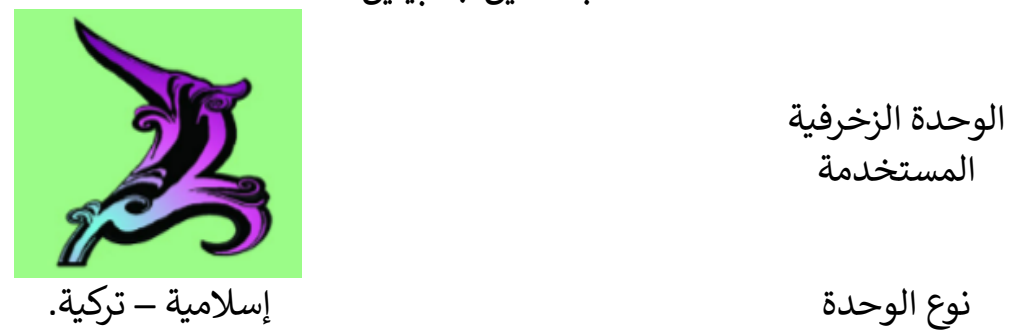

(5)

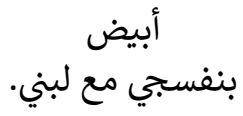

JHE, 2021, 31(3): pp 132-160- يتم طباعتها في جامعة المنوفية، جميع حقوق الطبع محفوظة للمجلة. 

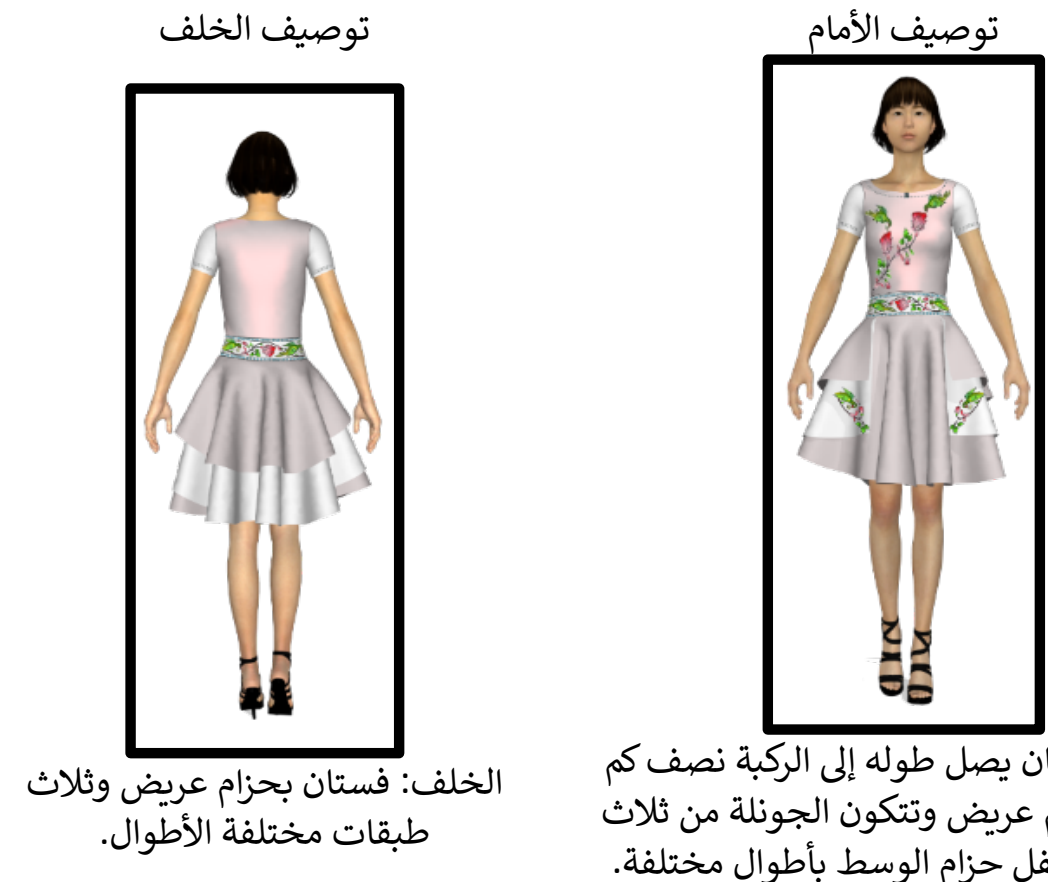

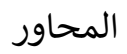

الأمام :فستان يصل طوله إلى الركبة نصف كم

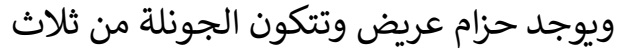
طبقات أسفل حزام الوسط وبن بأطوال مختلفة من ثلاث.

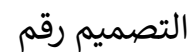

(6)

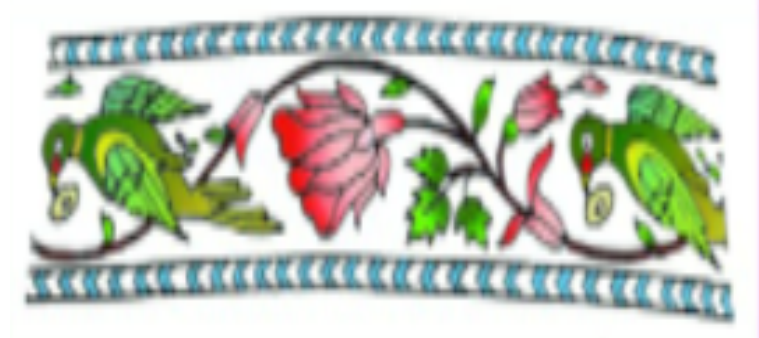

$$
\text { المستخدمة الزحدة }
$$

$$
\text { إسلامية - فارسية. }
$$

موجودة علي الصدر وحزام الوسط والطبقة الثانية.

$$
\text { لوزيع الوحدة لونية القخماش لون القماش }
$$$$
\text { ابيض - احمر فاتح. }
$$$$
\text { أخضر - أحمر. }
$$ 


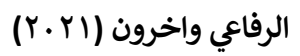
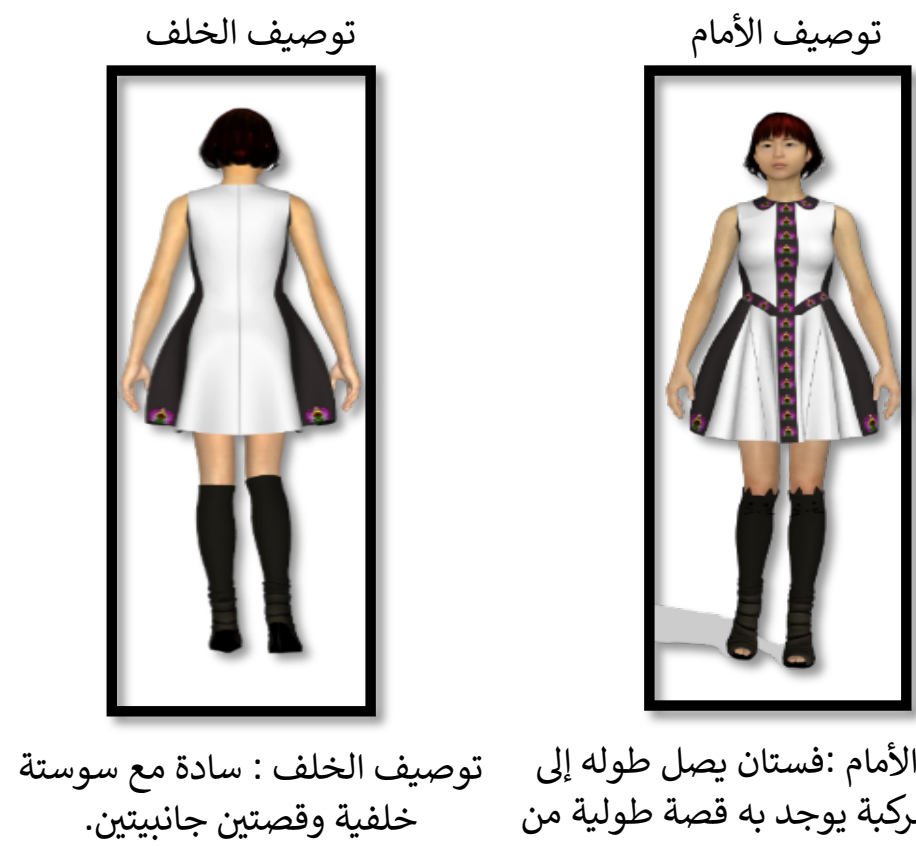

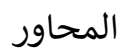

توصيف الأمام :فستان يصل طوله إلى منتصف الركبة يوجد به قصة الرمان طولية من فتحة الرقبة إلى نهاية الفستان والياقة بيضاوية ويوجد قصتين جانبيتين.

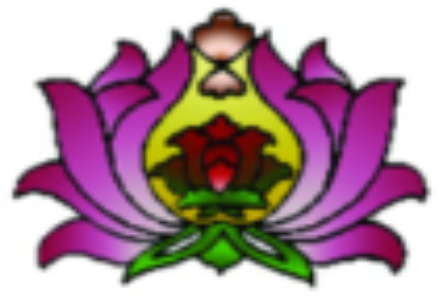

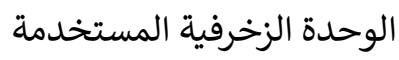

$$
\text { إسلامية - فارسية. }
$$

نوع الزخرفة المستخدمة

توزيع الوحدة الزخرفية

$$
\text { نوع القماش المقترح }
$$

موجودة على الياقة والقصة الطولية ومنطقة الوسط وأسفل الفستان على شكل

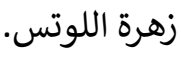

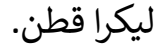

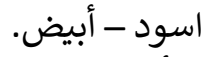

أصفر - أخضر - بنفسجي. 

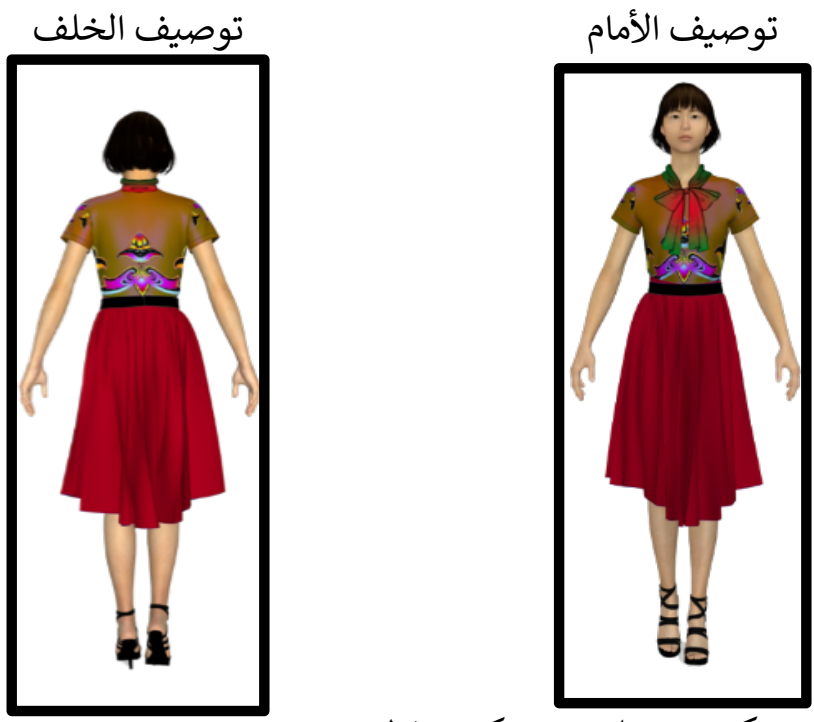

المحاور

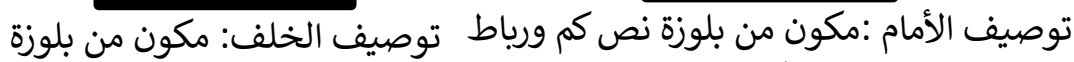
عنق على شكل فيونكة وجيبة كمر عريض. نص كم سورة سادة وجيبة كمر عريض.

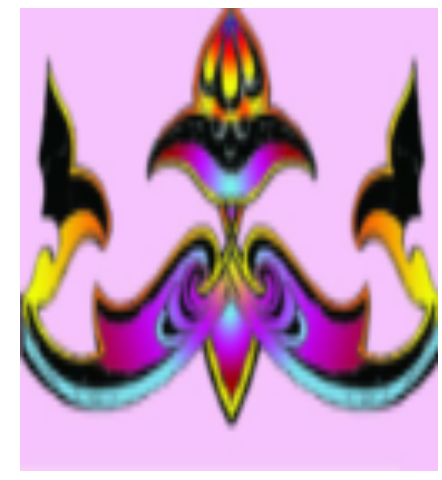

توصيف التصميم رقم (8)

$$
\text { إسلامية - تركية. }
$$

موجودة على جانبي الكم وعلى البلوزة من الأمام والخلف.

ستان ليكرا (البلوزة والجيبة). البلوزة بني فاتح.

$$
\text { ازرق فاتح - أصفر - بنفسبية بنيتي - أسود. }
$$

$$
\text { الوحدة الزخرفية }
$$

نوع الوحدة المستخدمة توزيع الوحدة الزخرفية نوع القماش المقترح الوحة المخرية

لون القماش

لون الزخرفة 


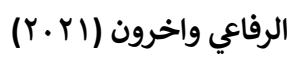
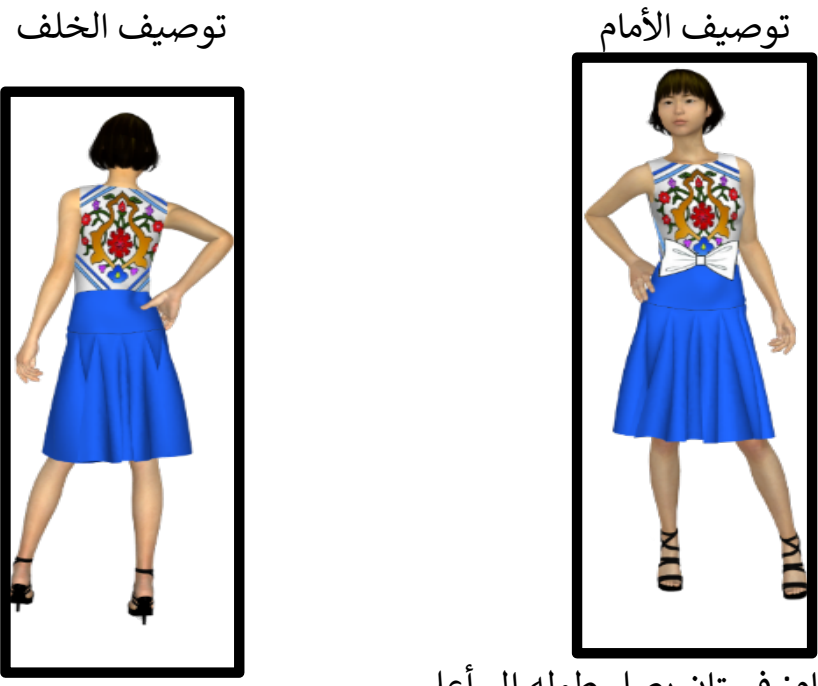

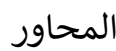

توصيف التصميم رقم

(9)

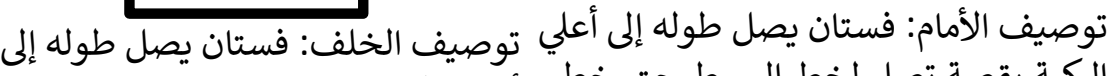

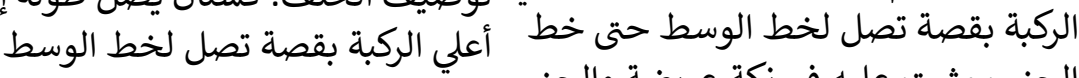

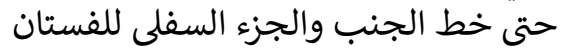
عبارة عن كالونيهات متعددة.

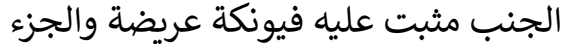
السفلي للفستان عبارة عن كالونيهات

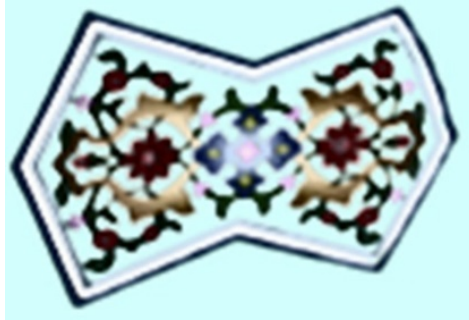

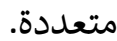

$$
\begin{aligned}
& \text { إسلامية - فارسية. } \\
& \text { موزعة على الأمام والخلف. } \\
& \text { ستان ليكرا. } \\
& \text { أبيض وازرق. } \\
& \text { أصفر - أزرق - أحمر. }
\end{aligned}
$$

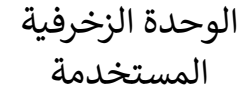

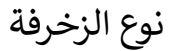
المستخدمة المخدة توزيع الوحدة الزخرفية نون القماش

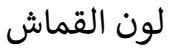
لون الزخرفة 


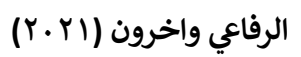
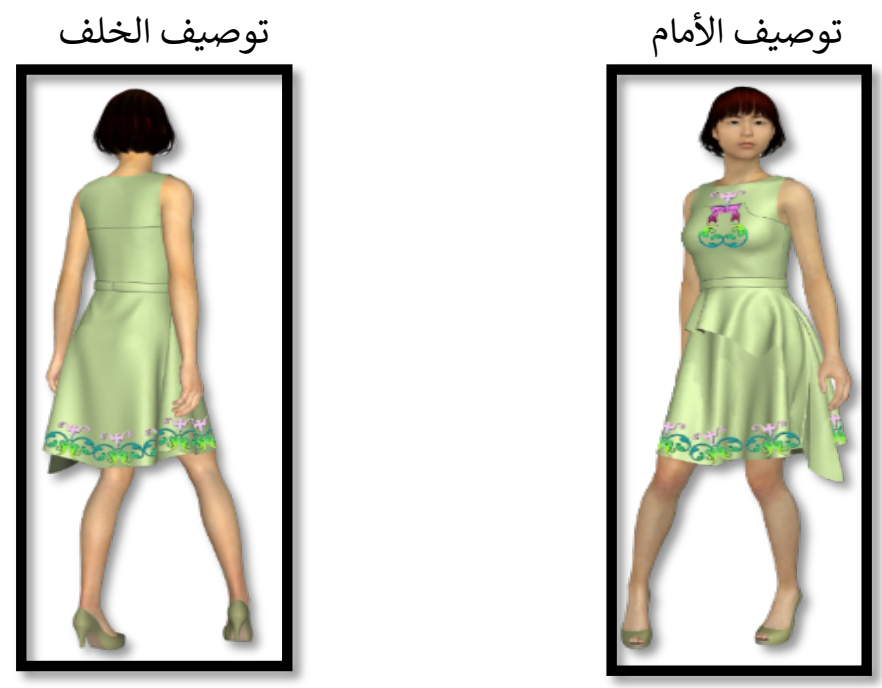

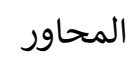

توصيف التصميم

(10)

توصيف الخلف: قصة عرضية وتمتد من الصدر وحزام.

توصيف الامام :فستان يصل طوله إلى أعلي

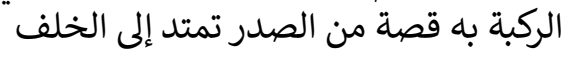
وتوجد حزام على الوسط والجزء السفلي به الهيه فالونه قصيرة مثبتة.

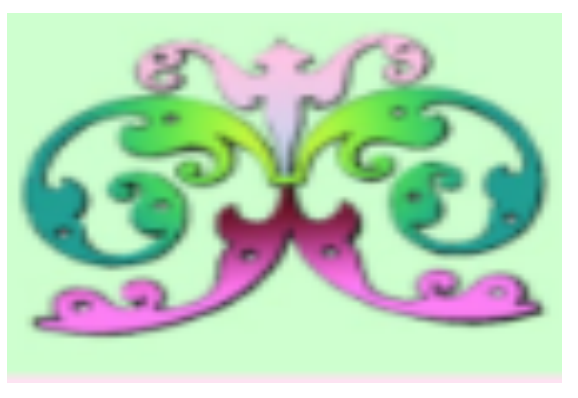

$$
\text { الوحدة الزخرفية }
$$

$$
\text { إسلامية - تركية. }
$$

$$
\text { توزيع الوحتخدة الزخرفة }
$$$$
\text { موزعة علي الصدر وأسفل الفستان. }
$$$$
\text { ليكرا قطن. }
$$$$
\text { أخضر فاتح. }
$$$$
\text { أخضر - أزرق - بنفسجي. }
$$ 


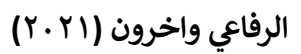
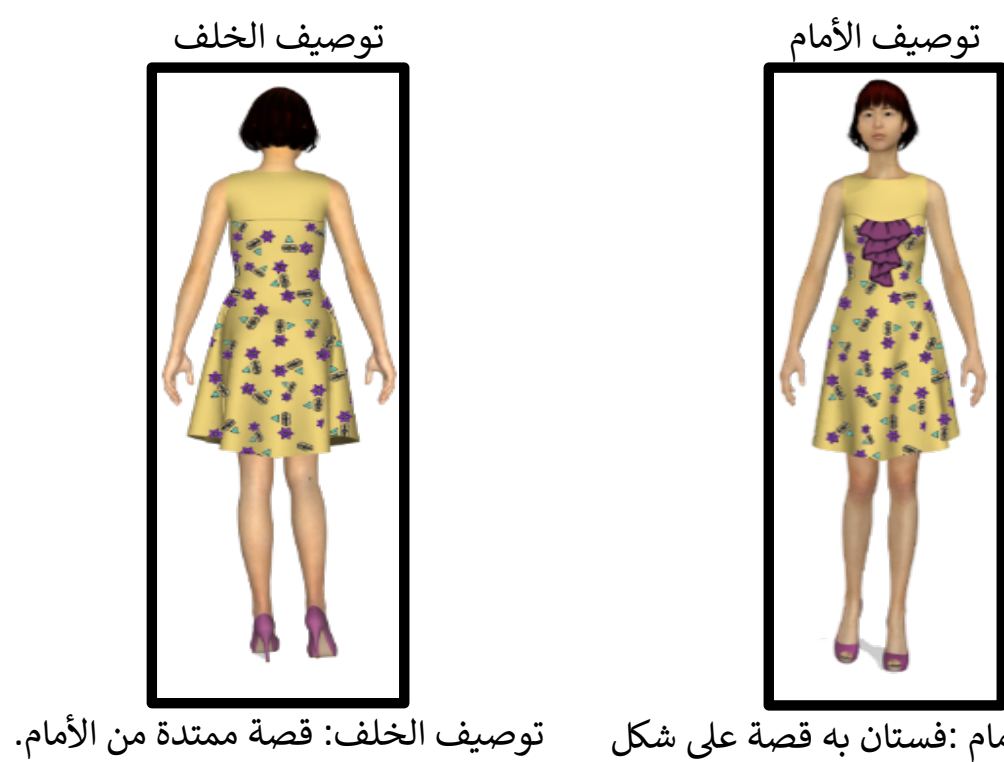

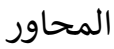

توصيف الأمام :فستان به قصة على شكل منحني مقلوب ومثبت عليه فالونه طولية.

توصيف التصميم

(11)
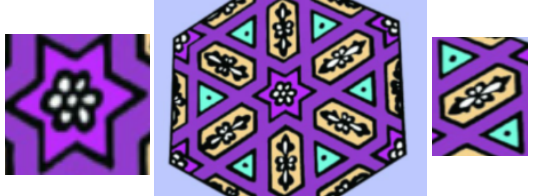

$$
\text { الوحدة الزخرفية }
$$

$$
\text { إسلامية - فارسية }
$$

$$
\begin{aligned}
& \text { نوع الوحدة } \\
& \text { الزخرفية } \\
& \text { توزيـ الوحدة } \\
& \text { الزخرفية } \\
& \text { نوع القماش } \\
& \text { المقترح } \\
& \text { لون القماش }
\end{aligned}
$$$$
\text { أصفر فاتح. }
$$$$
\text { أصفر - بنفسجي. }
$$ 


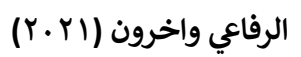

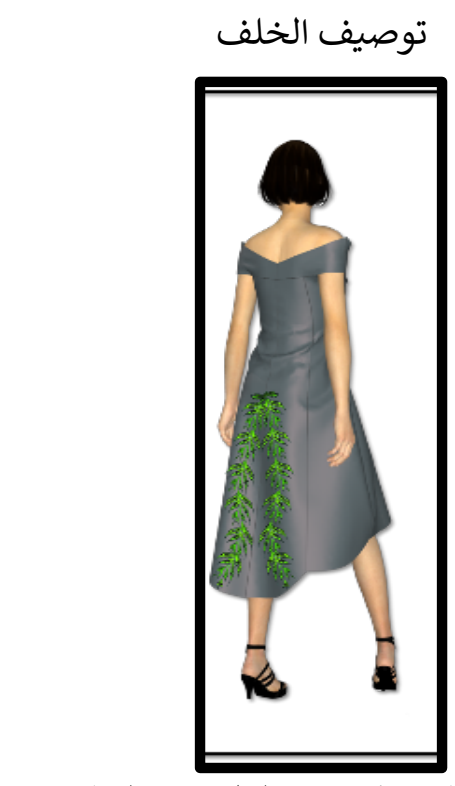

توصيف الأمام

المحاور

توصيف الخلف: قصتين طوليتين وطويل من منتصف الخلف. فين طولينين

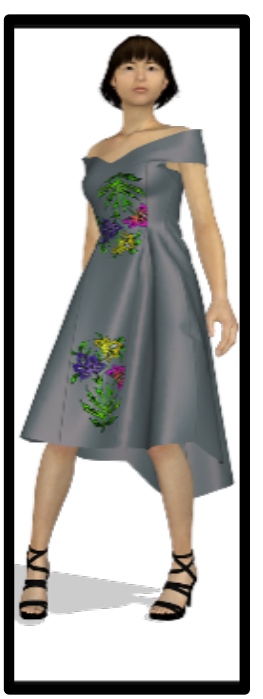

توصيف الأمام : فستان قصير من الامام

توصيف التصميم

(12) طويل من الخلف يوجد قصتين طويلتين.

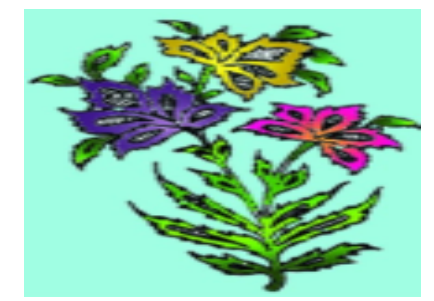

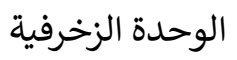 المستخدمة الزخفية}

$$
\text { إسلامية - فارسية }
$$

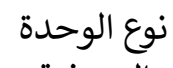

الزخرفية

موزعة علي الصدر وأسفل الفستان من الأمام وأسفل الخلف.

توزيع الوحدة الزخية

الزخرفية

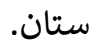

نوع القماش

المقترح

أخضر - أحمر - بنفسبي - غامق. أصفر.

لون القماش المقرح

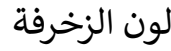

JHE, 2021, 31(3): pp 132-160- يتم طباعتها في جامعة المنوفية، جميع حقوق الطبع محفوظة للمجلة. 


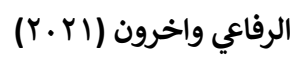

توصيف الخلف

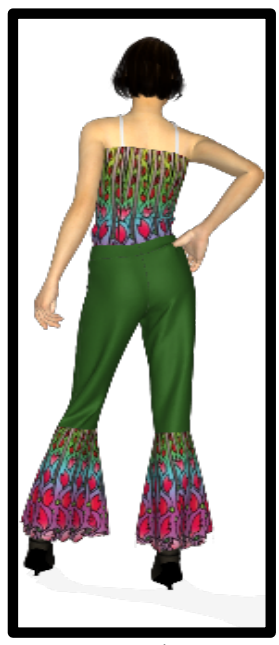

توصيف الأمام

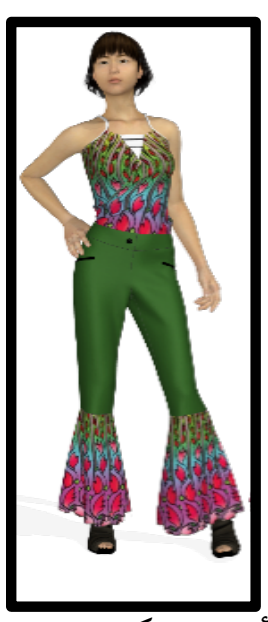

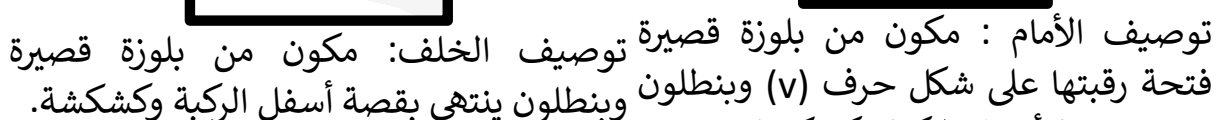
ينتهي بقصة أسفل الركبة وكشكشة شئه
المحاور

توصيف التصميم

(13)

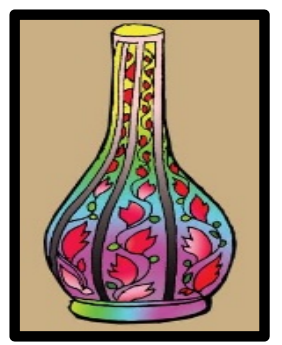

$$
\text { الوحدة الزخرفية }
$$

$$
\text { إسلامية - فارسية. }
$$

موزعة على البلوزة كلها أمام والخلف وعلى الكشكشة في البنطلون.

$$
\text { ليكرا. }
$$

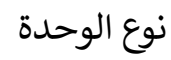

الزخرفية

توزيع الوحدة

الزخرفية

نوع القماش

المقترح

البلوزة منقوشة أخضر ولبني واحمر.

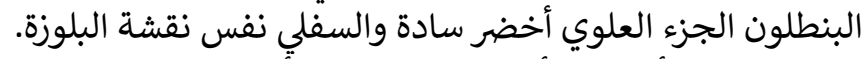

لون القماش

لون الزخرفة 


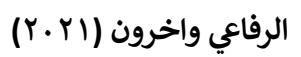

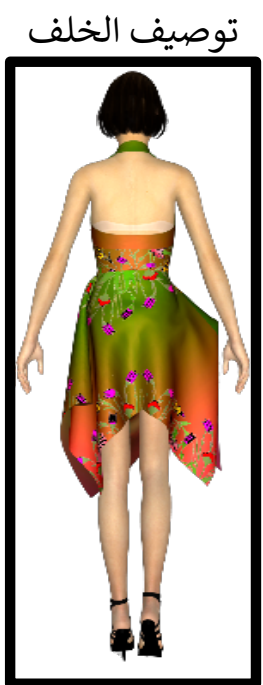

توصيف الخلف: يصل طوله أعلي الركبة

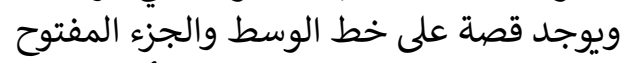
مثبت لخياطة على الجانب الأيسر.
توصيف الأمام

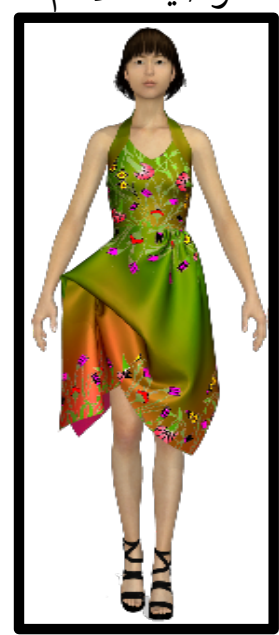

توصيف الأمام : يصل طوله أعلي الركبة

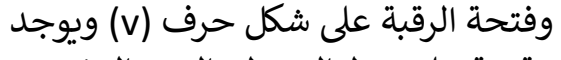
قصة على خط الوسط والجزي المئ المفتوح مثبت لخياطة على الجانب الأيسر.

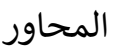

توصيف التصميم

(14)

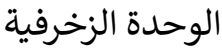 \\ المستخدمة الرخفية}

$$
\text { إسلامية - فارسية }
$$

$$
\begin{aligned}
& \text { نوع الوحدة } \\
& \text { الزخرفية } \\
& \text { توزيع الوحدة } \\
& \text { الزخرفية } \\
& \text { نوع القماش المخرفية } \\
& \text { المقترح }
\end{aligned}
$$$$
\text { هافان - أخضر وزيتوني }
$$$$
\text { أخضر - أحمر - بنفسجي - أصفر }
$$ 


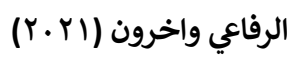

توصيف الخلف

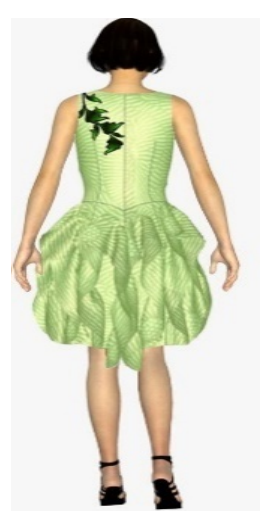

توصيف الأمام

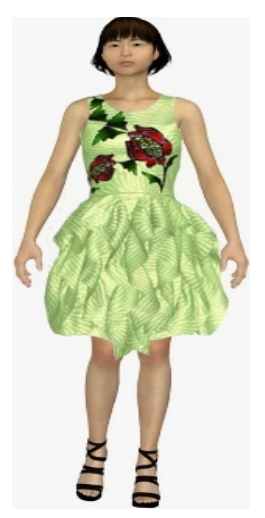

المحاور

توصيف التصميم

(15)

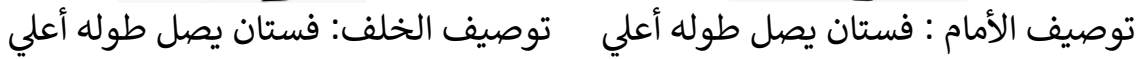

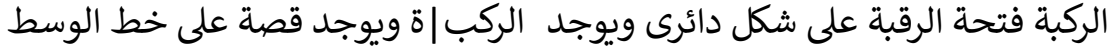

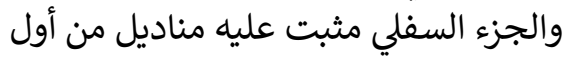

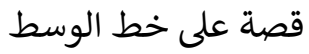

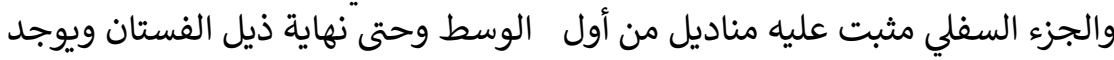

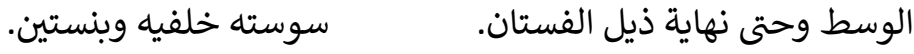

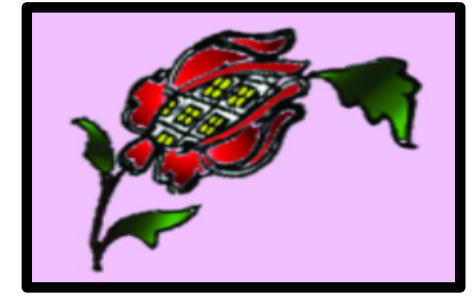

\section{الوحدة الزخرفية \\ المستخدمة الوحة الميه}

إسلامية - فارسية

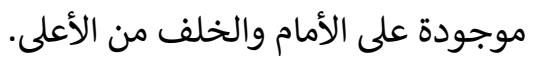

$$
\text { أخضيفون }
$$

$$
\begin{aligned}
& \text { نوع الوحدة } \\
& \text { الزخرفية } \\
& \text { توزيـح الوحدة } \\
& \text { الزخرفية } \\
& \text { نوع القماش } \\
& \text { المقترح } \\
& \text { لون القماش المقرح } \\
& \text { لون الزخرفة }
\end{aligned}
$$

النتائج والمناقشة

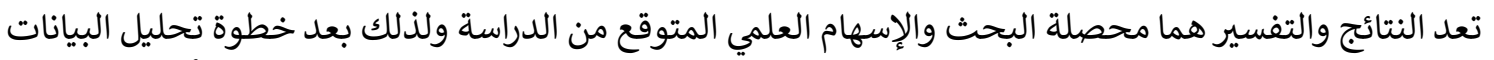

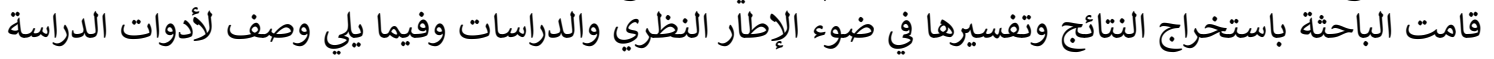

JHE, 2021, 31(3): pp 132-160- يتم طباعتها في جامعة المنوفية، جميع حقوق الطبع محفوظة للمجلة. 


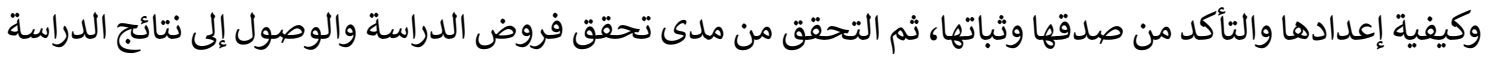

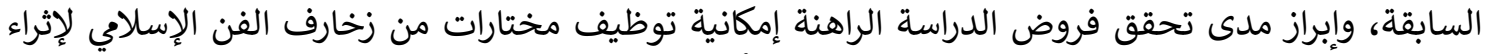

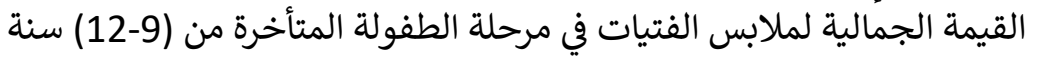

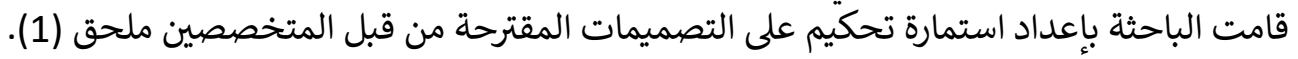

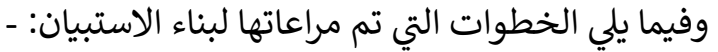

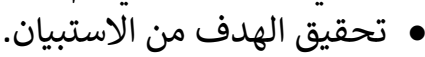

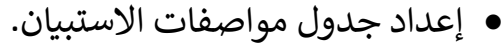
• • اختيار نوع بن ود الاستبيان وصياغتها.

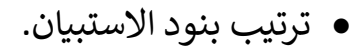

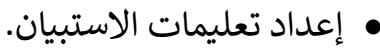

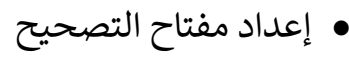
• وضع الاستبيان في صورته الأولية. • تجريب وتقنيين الاستبيان (ضبط الاستيان الاستبيان). • • • صياغة الاستبيان في صورتينه النهائية.

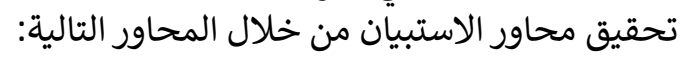

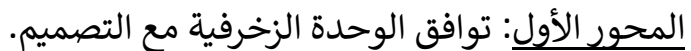

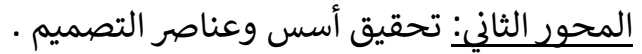

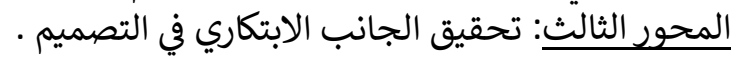
تم تقنين الاستبيان وذلك بتعيدين الجانب الصدين الصدق وآثبات الثبات له كما يأتى:

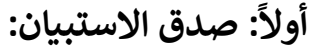

1. الصدق صدق الظاهرى (صدق الإنيان المتخصصين):

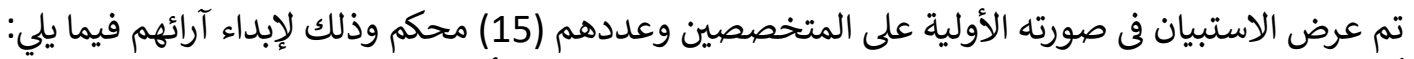

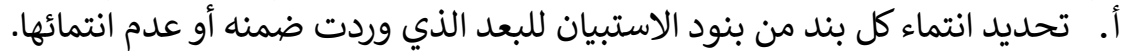

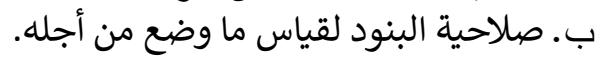

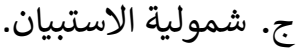

د. د. كفاية عدد العبارات لتوضيح الانيح المحور الذي يتضمنهان.

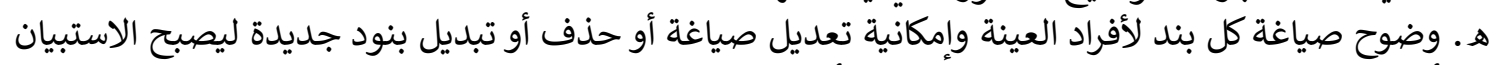

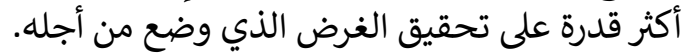

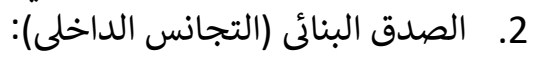

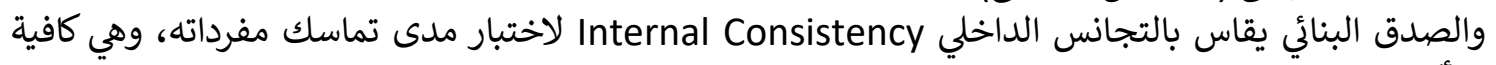
للتأكد من صدق الاستبيان الجديد.

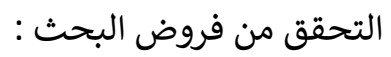

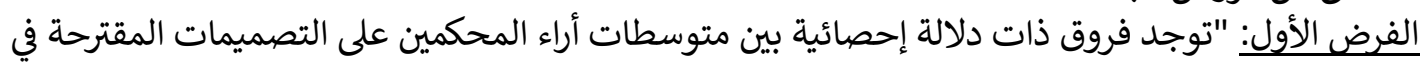

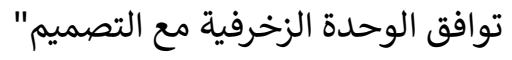

JHE, 2021, 31(3): pp 132-160- يتم طباعتها في جامعة المنوفية، جميع حقوق الطبع محفوظة للمجلة. 


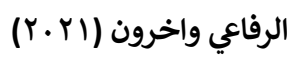

للتحقق من صحة هذا الفرض تم حساب المتوسط المرجح والمتوسط المئوي المرجح والانحراف المعياري لآراء

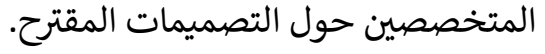

جدول (1) المتوسط المرجح والمتوسط المئوي المرجح والانحراف المعياري لآراء المتخصصين حول المول

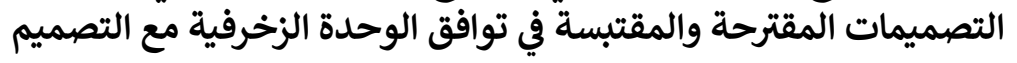

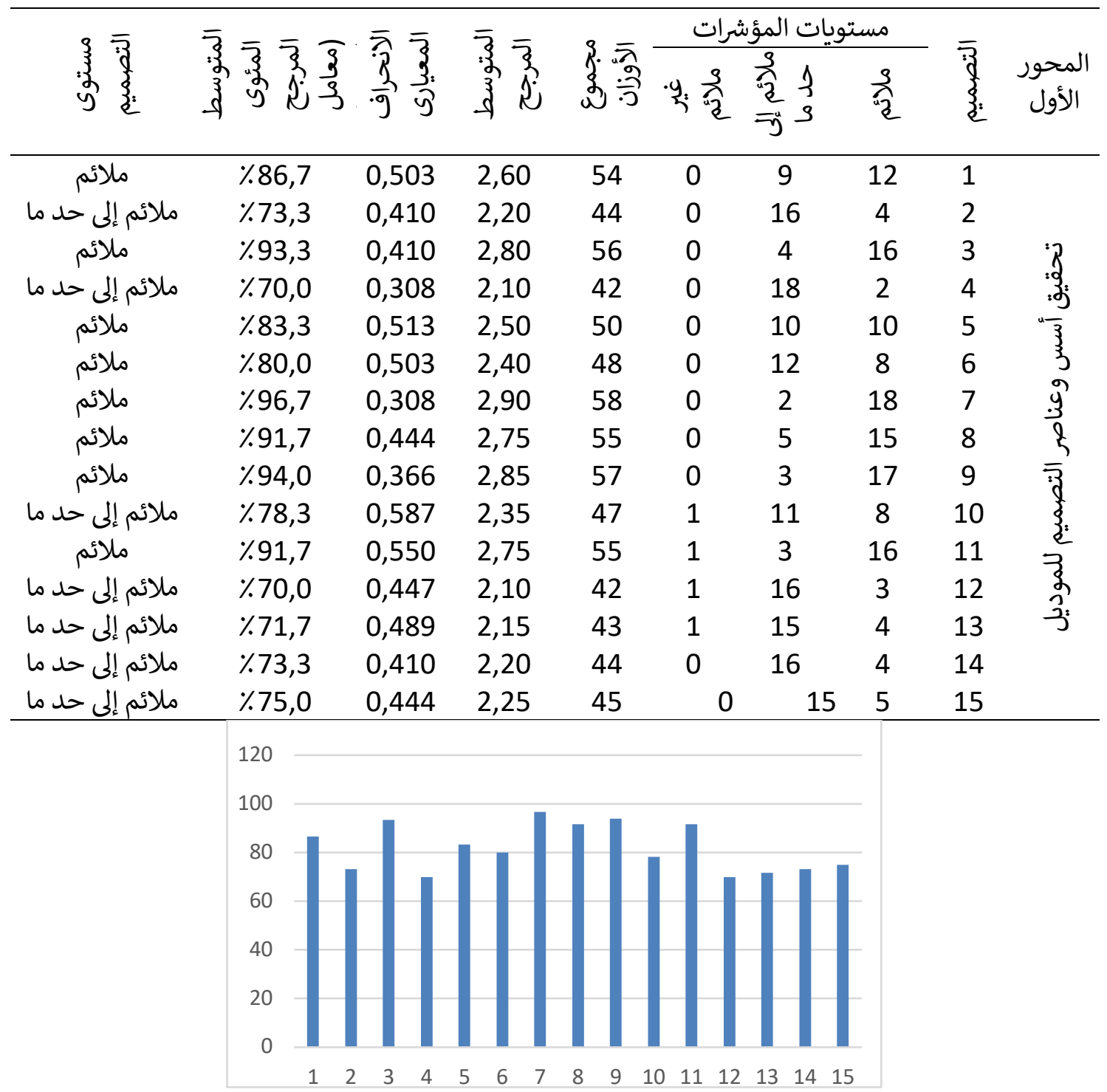

شكل (1) ترتيب التصميمات المقترحة وفق معاملات الجودة لآراء التخصصين في توافق الوحدة الزخرفية مع التصميم

JHE, 2021, 31(3): pp 132-160- يتم طباعتها في جامعة المنوفية، جميع حقوق الطبع محفوظة للمجلة. 
نستخلص من الجدول (1) والشكل (1):

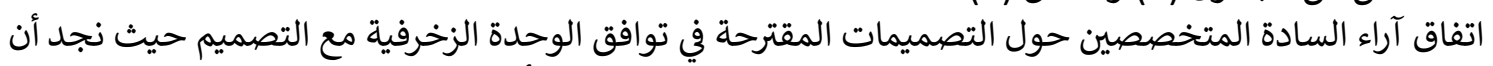

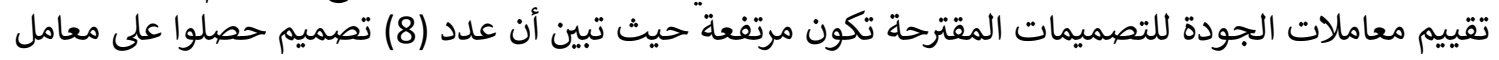

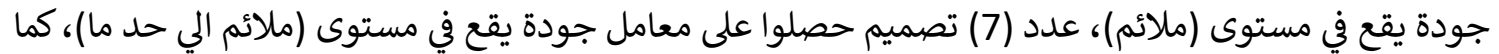

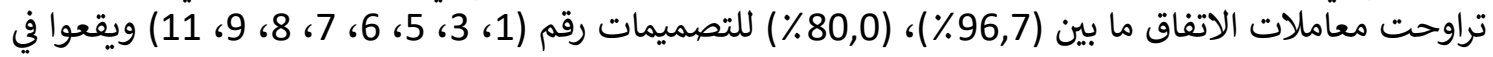

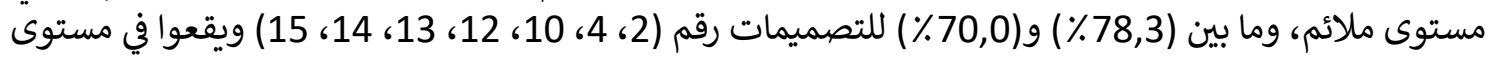

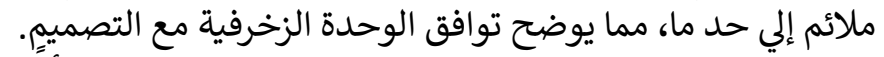

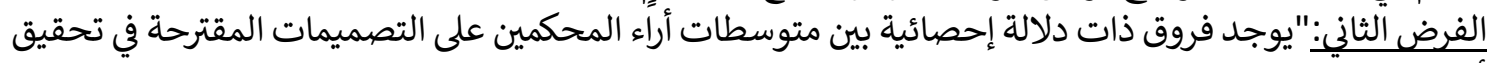

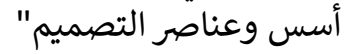
للتحقق من صحة هذا الفرض تم حساب المتوسط المرجح والمتوسط المئوي المرجح والانحراف المعياري لآراء المتخصصين حول التصميمات المقترح.

جدول (2) المتوسط المرجح والمتوسط المئوي المرجح والانحراف المعياري لآراء المتخصصين حول

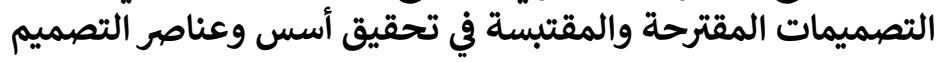

\begin{tabular}{|c|c|c|c|c|c|c|c|c|c|}
\hline \multirow[b]{2}{*}{ 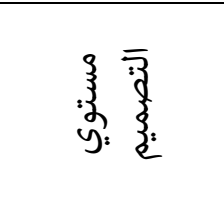 } & \multirow[b]{2}{*}{ 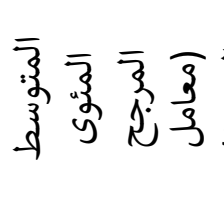 } & \multirow[b]{2}{*}{$\begin{array}{l}\overline{2} \\
\frac{2}{9} \\
\frac{3}{9}\end{array}$} & \multirow[b]{2}{*}{ 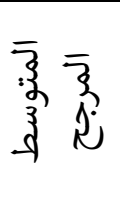 } & \multirow{2}{*}{ 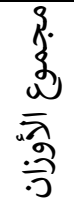 } & \multicolumn{3}{|c|}{ مستويات المؤشرات } & \multirow[b]{2}{*}{ 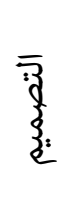 } & \multirow{2}{*}{$\frac{\overline{3}}{3}$} \\
\hline & & & & & 产: & $\begin{array}{ll}\frac{3}{4} & 1 \\
\frac{1}{2} & 3 \\
=3 & 3\end{array}$ & 条 & & \\
\hline 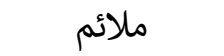 & $\% 83,3$ & 0,513 & 2,50 & 50 & 0 & 10 & 10 & 1 & \\
\hline ملائم إلى حد ما & $\% 73,3$ & 0,523 & 2,20 & 39 & 1 & 14 & 5 & 2 & \\
\hline 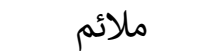 & $\% 90,0$ & 0,470 & 2,70 & 54 & 0 & 6 & 14 & 3 & \\
\hline ملائم إلى حد ما & $\% 73,3$ & 0,410 & 2,20 & 44 & 0 & 16 & 4 & 4 & $? R$ \\
\hline ملائم إلى حد ما & $\% 78,3$ & 0,587 & 2,35 & 47 & 1 & 11 & 8 & 5 & 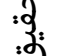 \\
\hline ملائم إلى حد ما & $\% 73,3$ & 0,523 & 2,20 & 44 & 1 & 14 & 5 & 6 & $4 \frac{3}{3}$ \\
\hline ملائم & $\% 96,7$ & 0,308 & 2,90 & 58 & 0 & 2 & 18 & 7 & j \\
\hline ملائم & $\% 93,3$ & 0,410 & 2,80 & 56 & 0 & 4 & 16 & 8 & .9 \\
\hline ملائم & $\% 88,3$ & 0,587 & 2,65 & 53 & 1 & 5 & 14 & 9 & b \\
\hline ملائم إلى حد ما & $\% 75,0$ & 0,550 & 2,25 & 45 & 1 & 13 & 6 & 10 & $\overline{3}$ \\
\hline ملائم & $\% 90,0$ & 0,571 & 2,70 & 54 & 1 & 4 & 15 & 11 & \{ \\
\hline ملائم إلى حد ما & $\% 68,3$ & 0,510 & 2,05 & 41 & 2 & 15 & 3 & 12 & $\dot{z}^{z}$ \\
\hline ملائم إلى حد ما & $\% 70,0$ & 0,447 & 2,10 & 42 & 1 & 16 & 3 & 13 & \\
\hline ملائم إلى حد ما & $\% 70,0$ & 0,447 & 2,10 & 42 & 1 & 16 & 3 & 14 & \\
\hline ملائم إلى حد ما & $\% 70,0$ & 0,553 & 2,10 & 42 & 2 & 14 & 4 & 15 & \\
\hline
\end{tabular}




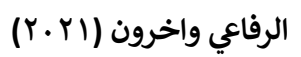

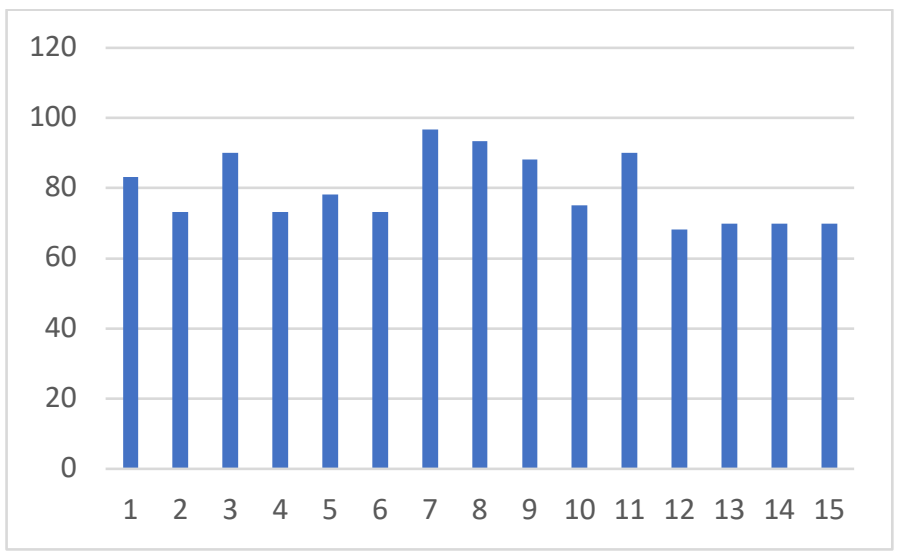

شكل (2) ترتيب التصميمات المقترحة وفق معاملات الجودة لآراء التخصصين في تحقيق أسس وعناصر التصميم

نستخلص من الجدول (2) والشكل (2):

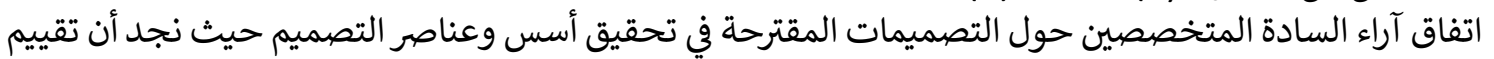

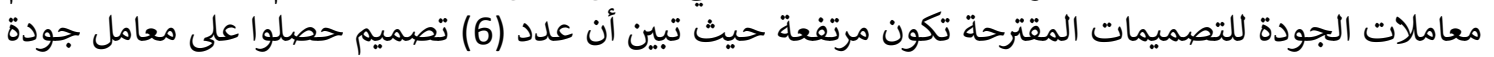

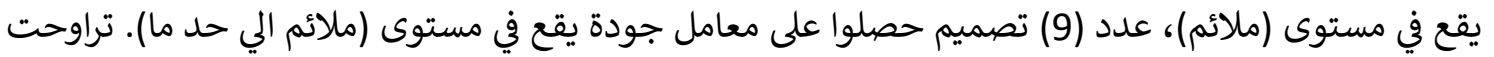

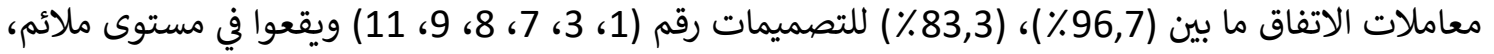

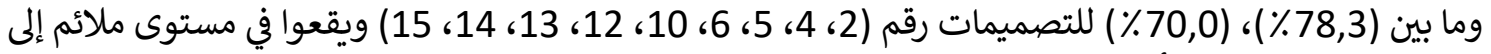

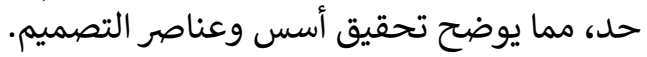

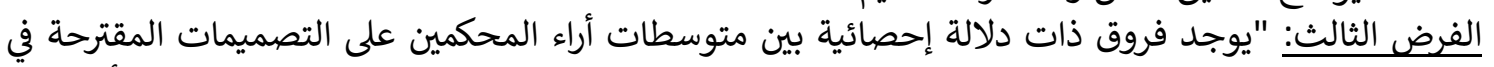

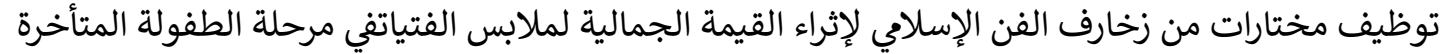

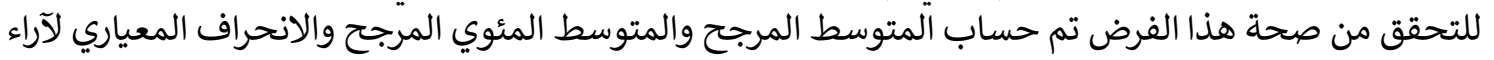

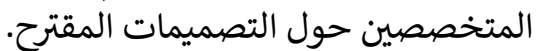
نستخلص من الجدول (3) والشكل (3):

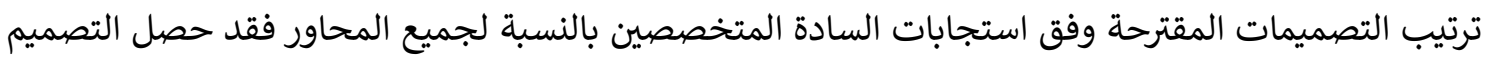

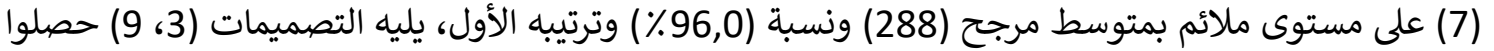

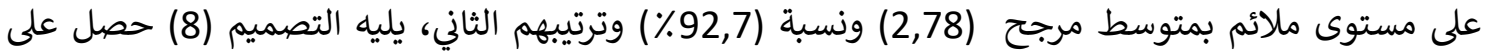

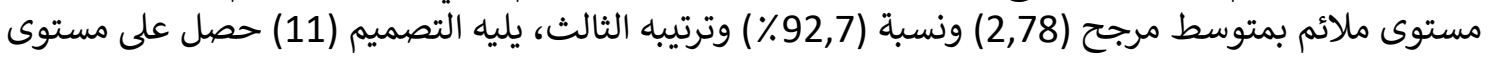

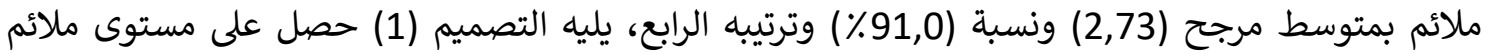

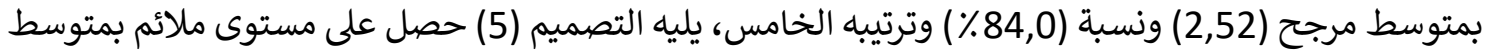
مرجح (2,43) ونسبة (81,0\%) وترتيبه السادس. 
جدول (3) المتوسط المرجح والمتوسط المئوي المرجح وترتيب التصميمات المقترحة المقتبسة في المارئ

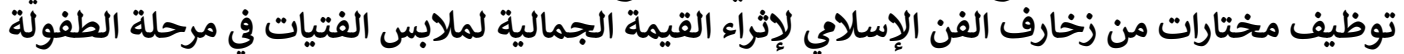
المتأخرة

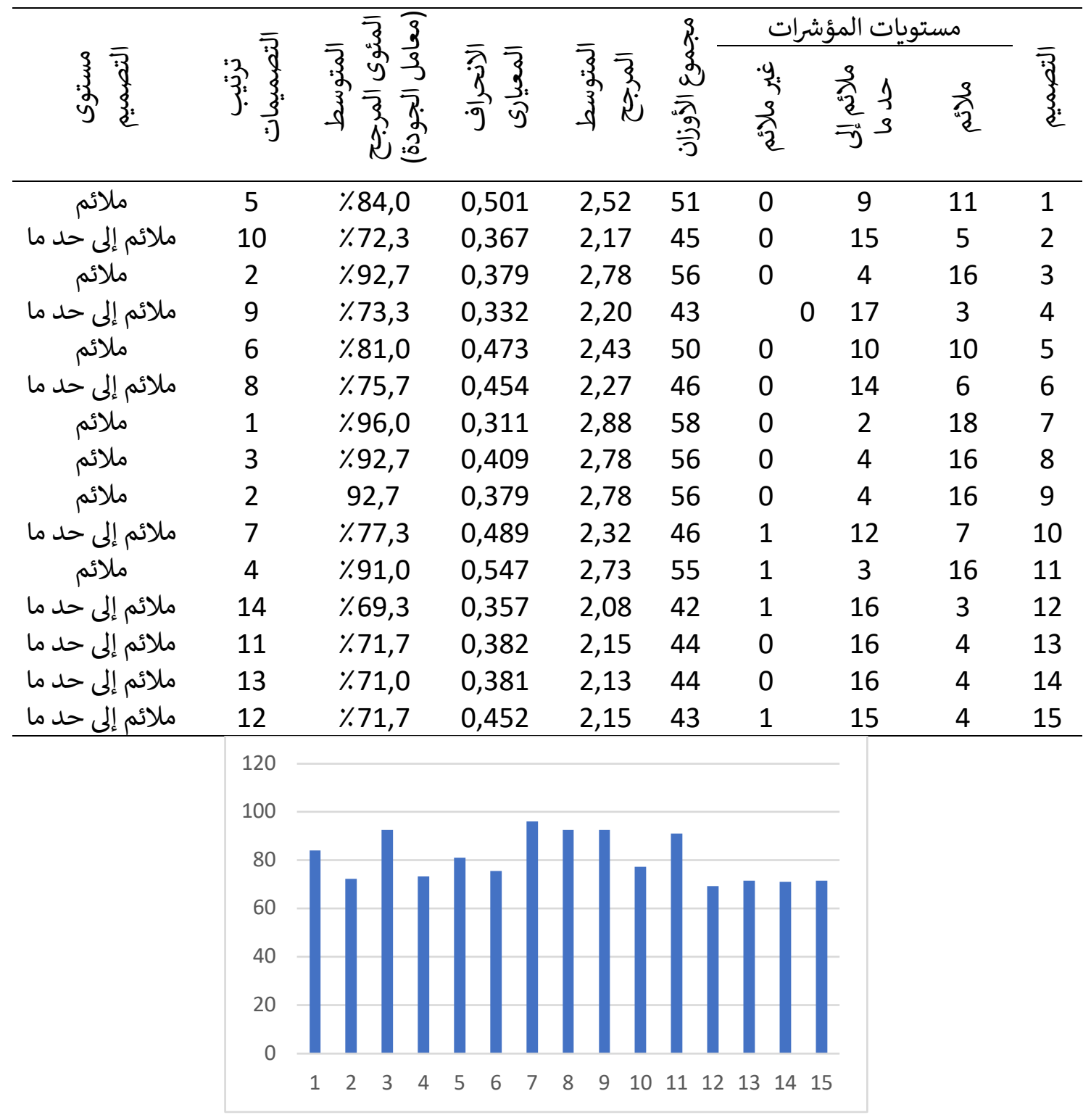

شكل (3) وترتيب التصميمات المقترحة والمقتبسة في توظيف مختارات من زخارف الفن الإسلامي لإثراء القيمة الجمالية لملابس الفتيات في مرحلة الطفولة المقلة المتأخرة 


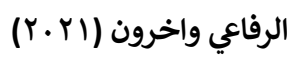

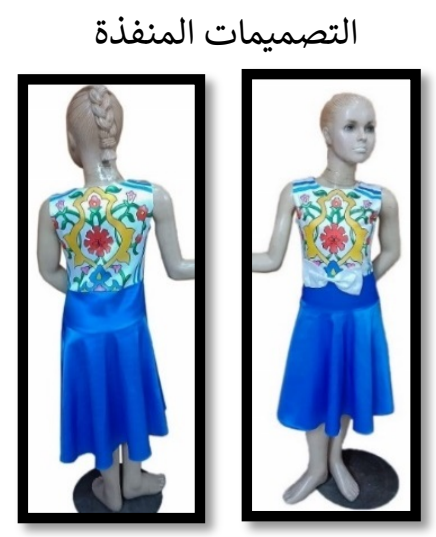

صورة رقم (1) توضح التصميم التاسع وحاصل على أعلى تقييم وفقا لآراء المحكمين

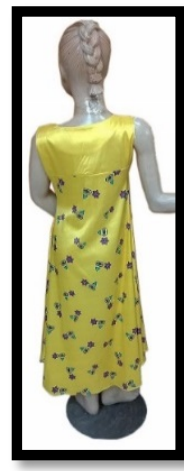

صورة رقم (3) توضح التصميم الحادي عشر وحاصل على أعلى أعلى التيم تقييم وفقا لآراء المحكمين

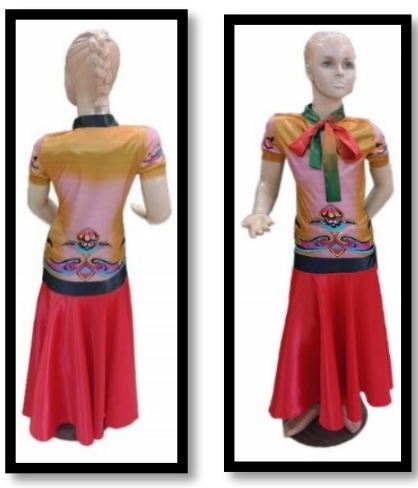

صورة رقم (2) توضح التصميم الثامن وحاصل على أعلى تقييم وفقا لآراء المحكمين

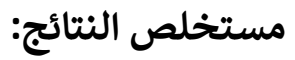

1- اتفاق آراء السادة المتخصصين حول التصميمات المقترحة في توافق الوحدة الزخرفية مع التصميم حيث نجديد

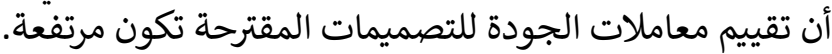

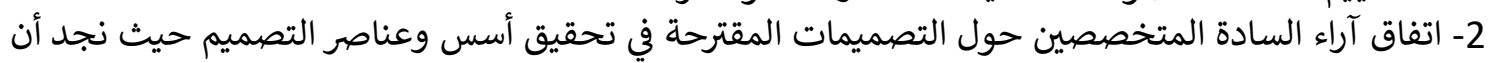

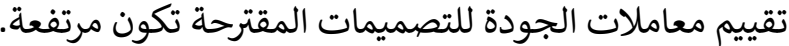

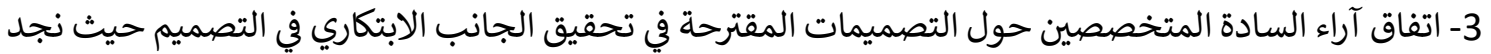

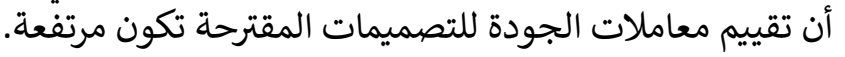

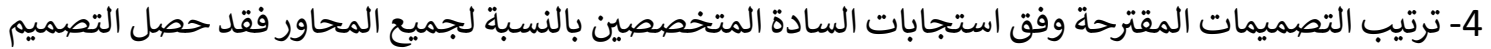

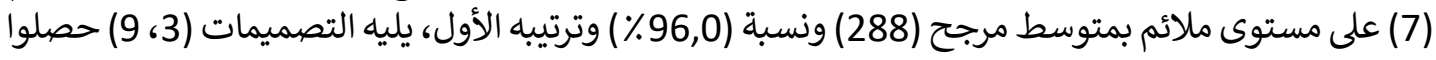


على مستوى ملائم بمتوسط مرجح (2,78) ونسبة (92,7\%) وترتئيهم الثاني، يليه التصميم (8) حصل على

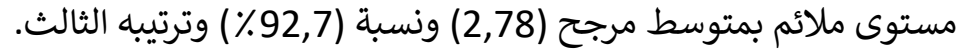

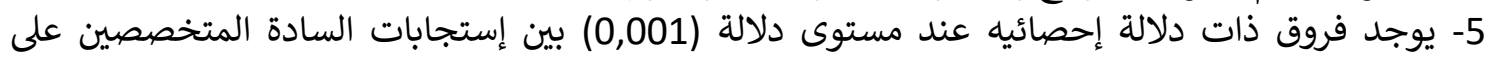

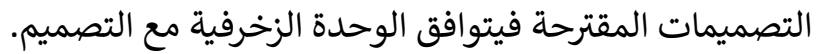

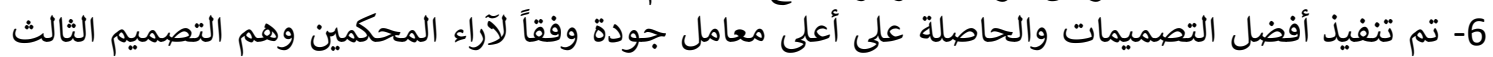
والتصميم السابع والتصميم التاسع. تصنيف التصيمات والحاصل

\section{التوصيات}

• ضرورة الاهتمام بتدريس البرامج الخاصة والحديثة لرسم التصميمات والزخارف المختلفة على ماكينة الطباعة

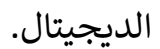
• ضرورة الاهتمام بالتكنولوجيا الحديثة وإدخالها في مختلف صنالف صناعات الفات الملابس.

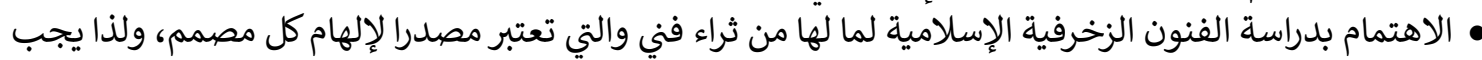

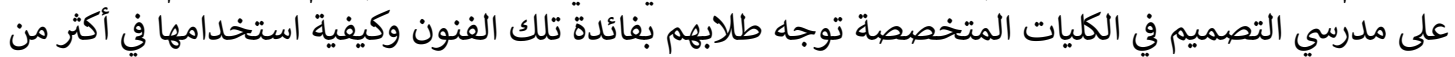

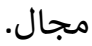
• إلقاء الضوء على ملابس الأطفال ودورها في تحقيق التوازن النفسي والاجتماعي لدى الأطفال في مرحلة الطفولة

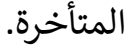
المراجع:

1- إيهاب فاضل أبو موسي: "تصميم الأزياء وتطويرها"، الطبعة الأولي، دار الزهراء الرياض، (2008).

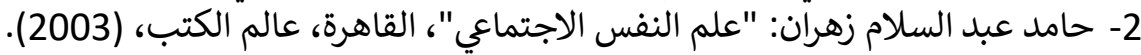

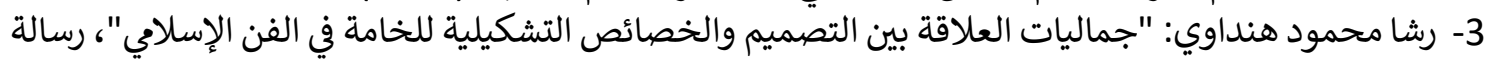

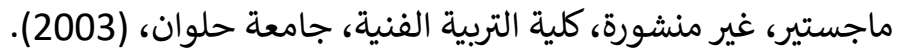

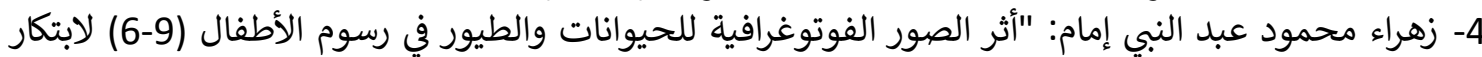

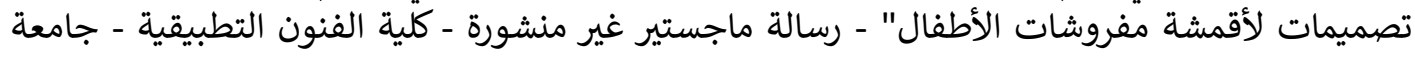
حلوان، (2006).

5- علي احمد الطايش: "الفنون الزخرفية الإسلامية المبكرة (في العصرين الأموي والعباسي)، زهراء الشوق للنشر، التقاهرة، (2002).

6- عفاف كمال علي: "إمكانية الحصول على تأثيرات الأثات جمالية ووظيفية جديدة مستوحاة من الفنون الحديثة

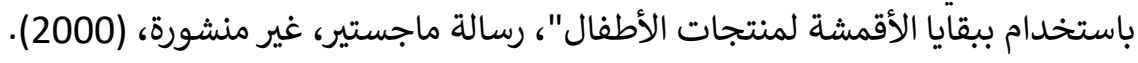

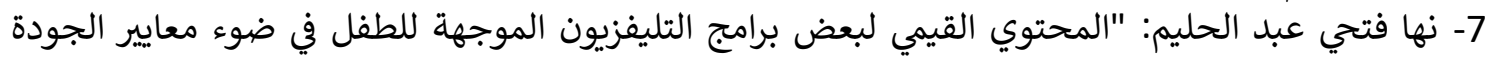
الشاملة"، رسالة دكتوراه، غير منشورة، كلية التربية النوعية، جامعة المنوفية، (2012). 
استمارة تحكيم التصميمات

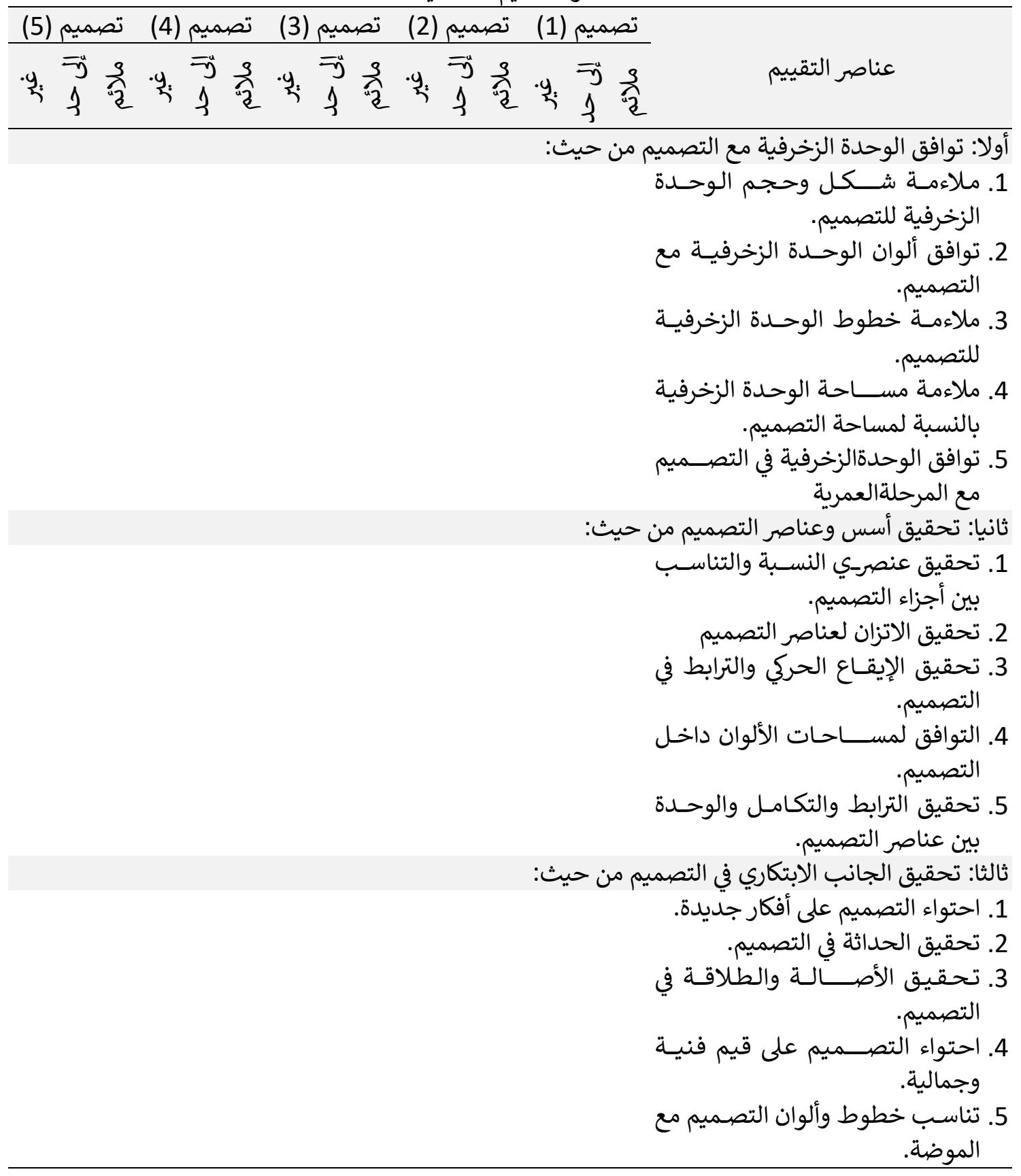

JHE, 2021, 31(3): pp 132-160- يتم طباعتها في جامعة المنوفية، جميع حقوق الطبع محفوظة للمجلة. 


\title{
Employ a Selection of Motifs of Islamic Art to Enrich the Aesthetic Value of the Girls' Clothes in the Late Childhood.
}

\author{
Nashaat N. AlRifai, Mona H. El Faramawy, Magda I. Al Aswad, Shimaa S. Zahra
}

Department of Clothing and Textile, Faculty of Home Economics, Menoufia University, Shibin El Kom, Egypt

\begin{abstract}
:
Islamic art is considered a fertile, specific and inexhaustible source for innovation in the field of girls 'clothing. Childhood is considered one of the most important stages in the formation of an individual's personality, which is shaped by the experiences of his social upbringing. Childhood has received the attention and care of specialists. Decorative; Which can be used and employed in clothes, increasing its prosperity, and working to enrich those clothes aesthetically and artistically, goal: The current research aims to obtain designs for children's clothes by using Islamic motifs and printing them on some of their clothes, by making a group of (15 designs) designs by making use of the decorations of Islamic arts in the field of clothing in the style of digital printing, the main adding a new vision for children's clothes inspired by the motifs Islamic art, and proposing some suitable designs for the child's clothes and taking into account his requirements and psychological, clothing and age needs, and the research sample was a group of children (girls) in late childhood, The research followed the descriptive and analytical approach with application by combining modernity and originality in selecting some attractive Islamic motifs from Persian and Turkish and employing them in designs suitable for the late childhood stage, and the study tools were a questionnaire to evaluate the designs proposed by a group of referees members of the faculty of the specialized colleges and their number (15 Arbitrator), and the results of the research came to fulfill the hypothesis as follows: There are statistically significant differences between the success of the proposed designs and the achievement of the foundations and elements of the design, the innovative element, and the achievement of the functional aspect of the design.
\end{abstract}

Key words: Islamic art, decorative design, late childhood, Islamic decoration. 